\title{
Dysfunctions, Molecular Mechanisms, and Therapeutic Strategies of Regulatory T Cells in Rheumatoid Arthritis
}

\author{
Xiaoya $L^{1,2 \dagger}$, Huihui $X u^{3+}$, Jing Huang ${ }^{4}$, Dan $L u o^{5}$, Shuang $L v^{2}$, Xiangchen $L u^{2,4}$ and \\ Cheng Xiao ${ }^{2,6 *}$
}

${ }^{1}$ The Institute of Medicinal Plant Development, Chinese Academy of Medical Sciences/Peking Union Medical College, Beijing, China, ${ }^{2}$ Institute of Clinical Medical Sciences, China-Japan Friendship Hospital, Beijing, China, ${ }^{3}$ Beijing Key Laboratory of Research of Chinese Medicine on Prevention and Treatment for Major Diseases, Experimental Research Center, China Academy of Chinese Medical Sciences, Beijing, China, ${ }^{4}$ School of Traditional Chinese Medicine, Beijing University of Chinese Medicine, Beijing, China, ${ }^{5}$ Department of Ophthalmology, Traditional Chinese Medicine Hospital of Changping District, Beijing, China,

${ }^{6}$ Department of Emergency, China-Japan Friendship Hospital, Beijing, China

OPEN ACCESS

Edited by:

Jian Gao,

Second Affiliated Hospital of Dalian Medical University, China

Reviewed by:

Fangfei Li,

Hong Kong Baptist

University, China

Chunfang Liu,

China Academy of Chinese Medical

Sciences, China

*Correspondence:

Cheng Xiao

xc2002812@126.com

${ }^{t}$ These authors have contributed equally to this work

Specialty section:

This article was submitted to Inflammation Pharmacology,

a section of the journal

Frontiers in Pharmacology

Received: 28 May 2021

Accepted: 19 July 2021

Published: 26 August 2021

Citation:

Li X, Xu H, Huang J, Luo D, Lv S, LuX and Xiao C (2021) Dysfunctions,

Molecular Mechanisms, and

Therapeutic Strategies of Regulatory

$T$ Cells in Rheumatoid Arthritis.

Front. Pharmacol. 12:716081.

doi: 10.3389/fphar.2021.716081
Regulatory T cells (Tregs) represent a distinct subpopulation of $\mathrm{CD} 4^{+} \mathrm{T}$ lymphocytes that promote immune tolerance and maintain immune system homeostasis. The dysfunction of Tregs is tightly associated with rheumatoid arthritis (RA). Although the complex pathogenic processes of RA remain unclear, studies on Tregs in RA have achieved substantial progress not only in fundamental research but also in clinical application. This review discusses the current knowledge of the characterizations, functions, and molecular mechanisms of Tregs in the pathogenesis of RA, and potential therapies for these disorders are also involved.

Keywords: rheumatoid arthritis, Tregs, molecular mechanisms, dysfunctions, therapeutic strategies

\section{INTRODUCTION}

Rheumatoid arthritis (RA) is a chronic and inflammatory autoimmune disease characterized by persistent synovitis, systemic inflammation, and symmetrical joint involvement. With the development of the disease, osteoporosis also occurs as a complication, and in severe cases, it may develop into a functional disability (Deane and Holers, 2021). Globally, the incidence of RA in adults is $0.5-0.8 \%$ according to epidemiological surveys (Lo et al., 2021). Genetic and environmental factors are regarded as the main pathogenesis of RA. In recent years, commensal flora is also recognized as another important pathogenesis of RA (Chiang et al., 2019). Thus far, RA has been mainly treated with disease-modifying antirheumatic drugs (DMARDs), such as methotrexate and leflunomide, supplemented with nonsteroidal anti-inflammatory drugs (NSAIDs) and/or glucocorticoids to alleviate the condition, but it cannot be completely cured. New therapeutic methods, such as biological and cell therapies, are being explored and developed continuously. However, treatments have limited success with this disease.

The immune system maintains a delicate balance between immune activation and immunosuppression through cellular and molecular elements that recognize "cantankerous" antigens to guard the body against attack. Once this balance is disrupted, such as the loss of immunosuppression/self-tolerance, an attack is launched against the autologous tissue, resulting in RA. After regulatory $\mathrm{T}$ cells (Tregs) were identified as a specific subpopulation with suppressive capacity maintaining immune homeostasis, numerous studies have related Treg disorders to RA. 
This review focuses on the molecular mechanism of Tregs in immunosuppression and the roles of these cells in RA.

\section{HISTORY AND BASIC UNDERSTANDING OF TREGS}

Congenitally athymic nude mice have been used as a model of cell-mediated immunological deficiencies for four decades. Based on this model, Pelleitier M. et al. reinforced the hypothesis that spontaneous autoimmunity is partly associated with a T-cell deficiency (Pelleitier and Montplaisir, 1975). However, with continual in-depth research on the subtypes and functions of $\mathrm{T}$ cells, researchers have recognized that cellular immunological disorders are correlated with abnormalities in one subtype of T cells but not all kinds of T cells. In 1995, Sakaguchi S. et al. showed that subtype $\mathrm{CD} 4^{+} \mathrm{T}$ cells expressing $\mathrm{CD} 25$, which are defined as a functional subset of $\mathrm{CD}^{+}$non-helper $\mathrm{T}$ cells and now recognized as Tregs, maintain immunological self-tolerance, and are associated with various autoimmune diseases (ADs) (Sakaguchi et al., 1995). A work by Powrie F. et al. in 1998 and 2000 showed that interleukin (IL)-10 and cytotoxic T-lymphocyte antigen (CTLA)-4 are essential molecules in the function of Tregs (Asseman and Powrie, 1998; Read et al., 2000). During this time, Seddon B. et al. reported the significance of transforming growth factor (TGF)- $\beta$ to Tregs (Seddon and Mason, 1999). Immediately after these contributions, Shevach E. M. et al. reported the critical roles of glucocorticoid-induced tumor necrosis factor receptor (GITR) and IL-2 in Tregs in 2002 and 2004 (Mchugh et al., 2002; Thornton et al., 2004). In 2003, forkhead box P3 (Foxp3) was confirmed to play a dominant role in Tregs by multiple researchers, including Sakaguchi S., at the same time (Fontenot et al., 2003; Khattri et al., 2003). Although the recognition of Tregs has been recent, the physiological significance and immunosuppressive function of this subpopulation of $\mathrm{T}$ cells have been highly controversial.

At present, the mainstream view is that Tregs are a subgroup of $\mathrm{CD} 4^{+} \mathrm{CD} 25^{+} \mathrm{T}$ cells characterized by the expression of Foxp3. Due to its dominant role in the differentiation, maintenance, development, and functioning of Tregs, Foxp3 has been identified as the master transcription factor of Tregs at early time (Fontenot et al., 2003; Khattri et al., 2003). Tregs comprise approximately $1-3 \%$ and $5-10 \%$ of $\mathrm{CD}^{+} \mathrm{T}$ cell in humans and rodents, respectively. Based on their origin, Tregs can be classified into two subpopulations as follows: thymus-derived Tregs (tTregs), also called natural Tregs (nTregs); and induced Tregs (iTregs) or peripherally derived Tregs (pTregs). The tTregs are produced by the thymus and are functional immunosuppressive $T$ cells due to their stable Foxp3 expression with demethylation of Treg-specific semi-methylated regions at an early stage of differentiation, while iTregs differentiate from naive conventional T cells (Tconvs) in the periphery under certain conditions. Once activated, iTregs show a labile expression of Foxp3. Besides, Tregs can be defined by their function and expression of cell surface markers, and subtypes classified in this manner include activated Tregs (aTregs, $\mathrm{CD} 4^{+} \mathrm{CD} 25^{+} \mathrm{CD} 45 \mathrm{RA}^{-} \mathrm{Foxp}^{+}$) and resting Tregs (rTregs,

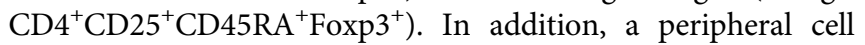

subset that neither expresses Foxp3 nor constitutively expresses CD25, but play the immunosuppressive role through IL-10, is considered to be another Treg cells, named T-regulatory Type-1 ( $\operatorname{Tr} 1)$ cells. Tr1 is not the dominant type in Tregs; thus, we mainly focus on Tregs expressing Foxp 3 and CD25 in the review. Although the Foxp3 expression is considered the most common marker and given the non-exclusivity of Foxp3 for Tregs in humans, a negative CD127 expression and even positive GITR expression have been regarded as markers for human Tregs by some researchers in recent years (Ronchetti et al., 2015; Giganti et al., 2021).

\section{MOLECULES RELATED TO THE GENERATION, PROLIFERATION, AND FUNCTIONAL MAINTENANCE OF TREGS}

The level of Tregs in the periphery is guaranteed to effectively exert immune tolerance effects. Generation and proliferation of Tregs involve complicated factors, and the main factors are discussed below. The molecules and corresponding functions are represented in Table 1. In addition, there are more mechanisms that regulate the number and function of Tregs, which are described in detail in Qi Jiang et al.'s review (Jiang et al., 2021).

\section{Foxp3}

Foxp3 is a member of the fork-head/winged-helix transcription factor family, and it encodes a $48-\mathrm{kDa}$ protein named scurfin and shows a selective expression in Tregs. As described above, Foxp3 has been identified as the most common marker and master transcription factor of Tregs, and it plays a vital role in the differentiation, phenotype, and functional maintenance of Tregs. A Scurfy gene deficiency leads to autoimmune lymphoproliferative syndrome in mice, while the adoptive transfer of Tregs into newborn mice with a Scurfy gene deficiency prevents the occurrence of autoimmune lymphoproliferative syndrome (Fontenot et al., 2003). In humans, both the deletion and mutation (I363V, R397W, and A384T) of the Foxp3 gene induce lymphoproliferative diseases, such as immunodysregulation, polyendocrinopathy, enteropathy, and X-linked syndrome (Gambineri et al., 2003). Moreover, Hayatsu N. et al. illustrated that the A384T mutation alters the interactions between Foxp3 and its specific target genes, including Batf, and that sequence-specific perturbations of Foxp3-DNA interactions influence Treg differentiation and accumulation (Hayatsu et al., 2017). In addition, Foxp3 is essential for the development of Tregs from naive $\mathrm{CD} 4^{+} \mathrm{CD} 25^{-}$ $\mathrm{T}$ cells. Retroviral gene transfer of Foxp3 converts naive $\mathrm{CD} 4^{+} \mathrm{CD} 25^{-} \mathrm{T}$ cells into a Treg phenotype similar with that of naturally occurring $\mathrm{CD}^{+}{ }^{+}$Tregs (Chai et al., 2005). Moreover, these cells produce cytokines, including IL-2 and IL-10, upon T-cell receptor (TCR) stimulation, and they express CD25 and CTLA-4, and inhibit the proliferation of effector T cells (Teffs) via cell-cell contact but not via a cytokine-independent mechanism (Yagi et al., 2004). Altogether, these findings lead to the conclusion that Foxp3 acts as a "master regulator" in Tregs. 
TABLE 1 | Molecules related to the generation, proliferation, and functional maintenance of Tregs.

\begin{tabular}{|c|c|c|}
\hline Molecules & Function in Tregs & Refs \\
\hline Foxp3 & Development, differentiation, phenotype, and functional maintenance & Chai et al., 2005; Hayatsu et al., 2017 \\
\hline IL-2 & Proliferation and functional maintenance & Snow et al., 2003; Setoguchi et al., 2005 \\
\hline TGF- $\beta$ & Proliferation and functional maintenance & Ghiringhelli et al., 2005; Oettel et al., 2016 \\
\hline GITR & Generation, differentiation, and functional maintenance & Carrier et al., 2012; Mahmud et al., 2014; Petrillo et al., 2015 \\
\hline $\mathrm{AhR}$ & Generation, differentiation, and functional maintenance & Gandhi et al., 2010; Ye et al., 2017; Lv et al., 2018; Zamali et al., 2019 \\
\hline \multicolumn{3}{|c|}{ Commensal flora } \\
\hline Bacteria & Generation and functional maintenance & Round et al., 2011; Telesford et al., 2015 \\
\hline Metabolites & Proliferation, differentiation, phenotype, and functional maintenance & Arpaia et al., 2013; Smith et al., 2013; Quintana, 2013; Singh et al., 2014 \\
\hline
\end{tabular}

\section{IL-2}

IL-2 is crucial for the maintenance and proliferation of Tregs both in vitro and in vivo. $\mathrm{CD} 4^{+} \mathrm{CD} 25^{+}$Tregs constitutively express CD25 (also called IL-2Ra), while Tregs produce low levels of IL-2. Therefore, the development and proliferation of Tregs rely on Teffs. The lack of IL-2, IL-2 receptor- $\alpha$ (IL-2R $\alpha$ ), or IL-2 receptor$\beta$ (IL-2R $\beta$; also called CD122) in mice induces fatal lymphoproliferative diseases accompanied by ADs (Horak et al., 1995). And injecting splenocytes or lymphocytes with IL-2 can prevent these disorders (Malek et al., 2002). A previous study has reported that an anti-IL-2 monoclonal antibody decreases the number of Tregs and inhibits physiological proliferation of these cells (Setoguchi et al., 2005). Signal transducers and activators of transcription 5 (STAT5) is an important molecule in the IL-2 pathway, which activates IL2-signaling by STAT5 phosphorylation. Similar to mice with a defect in the IL-2R $\beta$ expression, STAT5A/5Bdeficient mice suffer from a serious multi-organ immune disorder, and the number of Tregs in these mice is significantly decreased (Surbek et al., 2021).

\section{TGF- $\beta$}

TGF- $\beta$, which binds to heterodimer receptors I and II, phosphorylates Drosophila mothers against decapentaplegic protein (Smad) family members, ultimately regulating the transcription of related genes. Upon adequate stimulation, tTregs secrete TGF- $\beta$ and overexpress TGF- $\beta$ on the cell surface. There are two types of TGF- $\beta$ in Tregs, which are as follows: membrane-type TGF- $\beta$ and secreted-type TGF- $\beta$. Secreted-type TGF- $\beta$ mainly promotes the proliferation of Tregs (Ghiringhelli et al., 2005). TGF- $\beta$ participates in Foxp3 induction and the proliferation of iTregs by synergizing with IL-2 in the periphery, but it may not be responsible for the Foxp3 expression in tTregs in the thymus. $\mathrm{CD} 4^{+} \mathrm{CD} 25^{+}$Tregs from the thymus of dominant-negative TGF- $\beta$ receptor type II mice retain the ability to inhibit colitis. In contrast, Treg activity in the periphery is suppressed in these mice (Fahlen et al., 2005). In addition, TGF- $\beta$ mediates the Foxp 3 expression by activating the TCR, thus promoting the transformation of Teffs into CD4 ${ }^{+}$Foxp $^{+}$Tregs (Oettel et al., 2016).

\section{GITR}

GITR (also called TNFSF18 or CD357), a $22-\mathrm{kDa}$ protein belonging to the tumor necrosis factor receptor (TNFR) family, is constitutively expressed on Tregs, and is expressed at higher levels on Tregs (Shimizu et al., 2002). Decades of research have shown that GITR plays a crucial role in the differentiation of tTregs as well as the expansion and suppressive functions of both tTregs and pTregs (Carrier et al., 2012; Mahmud et al., 2014; Petrillo et al., 2015). After engrafting a bone marrow mixture from CD45.2 $2^{+}$GITR-deficient mice $\left(\mathrm{Gitr}^{-/-}\right.$) and CD45.1 $1^{+}$SJL wild-type congenic mice into RAG2 ${ }^{-/-}$irradiated recipient mice, the mature thymic $\mathrm{CD} 25^{+} \mathrm{Foxp}^{+}{ }^{+}$Tregs generated from the $\mathrm{Gitr}^{-1-}$ cells are approximately $70 \%$ of those produced from the wild-type cells (Mahmud et al., 2014). In addition, after the administration of GITR ligand (GITRL) antibodies to thymic organ cultures, the development of Tregs and the expression of Treg markers are suppressed (Mahmud et al., 2014). Furthermore, the number of IL-10-producing Tregs is increased in the spleen of GITRL-transgenic mice, which suppresses naive T-cell proliferation in an IL-10-dependent manner (Carrier et al., 2012). More importantly, high expression of GITR on Tregs is beneficial to the outcomes of several ADs, and the correlation between GITR $^{+}$Tregs and disease severity is more favorable than that between the CD25 expression on Tregs and disease severity based on cumulative studies (Bianchini et al., 2011; Petrillo et al., 2015). In RA, GITR + Tregs expand with an effective treatment, while $\mathrm{CD} 4^{+} \mathrm{CD} 25^{+} \mathrm{Foxp}^{+}{ }^{+}$Tregs cannot achieve a similar expansion (Alunno et al., 2010). Above all, it is not surprising that some researchers urge the scientific community to consider GITR to be a marker of human Tregs. However, it is worth noting that the effect of GITRL/GITR on $\mathrm{T}$ cells is context-dependent, specifically depending on the host environment and activation state of the Tregs and Teffs via the nuclear factor kappa-B (NFкB) (Ji et al., 2004; Iwaszkiewicz-Grzes et al., 2021).

\section{AhR}

AhR, the full form for the aryl hydrocarbon receptor, is a cytoplasmic receptor acting in both ligand-dependent and -independent manners, and it can be activated by exogenous and endogenous ligands coming from air pollutants, diet, host metabolism, and the intestinal microbiome. Once activated, the AhR migrates to the cell nucleus and induces transcription of ligand-metabolizing enzymes (cytochrome P1 family) as well as immunoregulatory and growth factors (IL-10, Arginase-1, IL-6, IL-22, and vascular endothelial growth factor) and the negative regulator of the AhR repressor (AhRR) pathway (Denison and Nagy, 2003). In pTregs, AhR is expressed more abundantly, and AhR-expressing Tregs enhance suppressive activity compared 
with Tregs lacking AhR expression in vivo (Ye et al., 2017). Via targeting glycolysis and the subsequent nicotinamide adenine dinucleotide (NAD) ${ }^{+} /$Sirtuin (SIRT) $1 /$ histone methyltransferase (SUV39H1)/H3K9me3 signaling pathway, the activation of AhR promotes Treg differentiation (Lv et al., 2018). Furthermore, the activation of AhR supports the de novo generation of Tregs and promotes the suppressive function in humans (Zamali et al., 2019). While in tTregs, by activating AhR via indoleamine 2,3dioxygenase (IDO) signal, the immunosuppressive function of tTregs is increased (Kumar et al., 2017). In Tr1 cells, the AhR increases the expression of IL-10, granzyme $\mathrm{B}$, and CD33 (a surface molecule contributes to the suppressive function of $\operatorname{Tr} 1$ cells). In addition, AhR activation also upregulates the expression of Tr1 autocrine growth factor IL-21 (Apetoh et al., 2010). Interestingly, some research studies found that AhR activation by agonist such as 6-formylindolo [3,2-b] carbazole interfered with the Treg development and increased the severity of autoimmune disease (Quintana et al., 2008). And other research studies got the same result that AhR causes opposite outcomes when activated by 6 -formylindolo [3,2-b] carbazole (FICZ) or tetrachlorodibenzo-p-dioxin (TCDD). Thus, AhR regulates Treg differentiation and function in a ligand-specific fashion (Gandhi et al., 2010) through different mechanisms, such as direct functional enhancements, induction of epigenetic modifications of Foxp3, and modulation of dendritic cells (DCs) (Quintana, 2013). Collectively, these findings suggest a role for the AhR in the control of functional Tregs, constituting a unique target for therapeutic immunomodulation.

\section{Commensal Flora}

With the increasing microbiota research studies, the relationship among saliva, respiratory, gut microbiota, their metabolites, and host immunity has been gradually revealed, and it has been found that the alternation of commensal flora is involved in the pathogenesis of RA, chronic colitis, cancer, and diabetes (Lynch and Pedersen, 2016). Among them, the relationship between intestinal flora and disease is the most concerning because intestinal flora not only causes diseases but also cures them. Bacteria and their metabolites enhance immune tolerance in the gut by affecting the differentiation and function of Tregs and partly by the AhR signal pathway.

Bacteroides fragilis can produce and export polysaccharide A (PSA), a capsular polysaccharide that is presented to naive $\mathrm{CD} 4^{+}$ $\mathrm{T}$ cells by DCs in the lamina propria (Telesford et al., 2015), and at the same time, PSA through a toll-like receptor (TLR)2 directly helps in the activation of TGF- $\beta$-induced Foxp $3^{+}$Tregs to facilitate the secretion of IL-10 and promote immunologic tolerance (Round et al., 2011; Telesford et al., 2015). Other researchers have demonstrated that Clostridium Faecalibacterium prausnitzii, but not related to Clostridia, skew human DCs to prime Tr1-like Tregs by TLR2/6 triggering, c-Jun N-terminal kinase (JNK) signaling, and CD39 ectonucleotidase activity (Alameddine et al., 2019). Besides, Campylobacterales can interfere with host immune in different ways. Their flagellins $\mathrm{C}(\mathrm{FlaC})$ can activate $\mathrm{p} 38$ and decrease the responsiveness of human macrophage-like cells toward the bacterial TLR4 agonist (Faber et al., 2016).
Metabolite studies have found that short-chain fatty acids (SCFAs), including acetic acid, butyric acid, and propionic acid, are the end metabolites of carbohydrates in intestinal flora (such as Clostridia) (Furusawa et al., 2013), which can interact with intestinal immune cells and play the role in maintaining immune tolerance to the intestinal flora. As the inhibitors of histone deacetylases (HDACs) and enhancers of histone $\mathrm{H} 3$ acetylation (AcH3), SCFAs increase Treg numbers, Foxp3 expression, and the suppressive function of Foxp $3^{+}$Tregs in an HDAC-dependent manner (Arpaia et al., 2013). In addition, as ligands for G protein-coupled receptors (GPCRs), SCFAs induce the differentiation of Tregs and $\operatorname{Tr} 1$ cells by increasing the expression of Foxp3 and upregulating the secretion of IL-10 and TGF- $\beta$ via GPCR41, GPCR43, and GPCR109 (Smith et al., 2013; Singh et al., 2014). Intestinal flora can also regulate the function of immune cells through other metabolites such as tryptophan derivatives. Tryptophan, an essential amino acid provided by dietary protein, is metabolized by several bacteria such as Bacteroides, Bifidobacterium, Clostridium, Peptostreptococcus, and Lactobacillus. Among metabolites from tryptophan, indole, and its derivatives, tryptamine, indole-3acetic acid (IAA), indole-3-aldehyde (IAld), 3-methyl-indole (skatole), indole-acrylic acid (IA), and indole lactic acid (ILA) are AhR ligands (Roager and Licht, 2018). Once activated, the AhR translocates to the nucleus and initiates gene transcription (cytochrome P450 (CYP) family, IL-10, and AhRR) to enhance the immunosuppressive function of Tregs (Denison and Nagy, 2003). Furthermore, the AhR also promotes $\mathrm{CD}^{+}$cells to differentiate into Tregs by interacting with DCs (Quintana, 2013) (Figure 1).

The immune regulation of bacteria in hosts is currently a hot research topic. More studies on the immune regulatory mechanism of pathogenic bacteria and probiotics are still needed. More importantly, whether basic research can be turned into clinical practice to benefit patients will be the focus in the early future.

\section{MOLECULAR MECHANISM OF THE IMMUNOSUPPRESSIVE FUNCTION OF TREGS}

The dominant function of Tregs is the control of all aspects of the immune response. Antigen presenting cells (APCs), such as DCs, macrophages, and $\mathrm{B}$ lymphocytes, are the primary targets of Tregs, and responder T cells, such as $\mathrm{CD} 4^{+} \mathrm{T}$ cells $\mathrm{Th}$ cells, $\mathrm{CD} 8^{+}$ $\mathrm{T}$ cells, and natural killer (NK) $\mathrm{T}$ cells, are efficient targets of Tregs. In addition, mastocytes, osteoblasts, and osteoclasts (OCs) are targets of Tregs. The mechanisms regulating these cell types are broadly classified as targeting $\mathrm{T}$ cells (the secretion of suppressive cytokines, disruption of metabolic processes, and induction of apoptosis) and targeting APCs (decreased costimulation or decreased antigen presentation).

\section{Expression of Suppressive Cytokines}

Tregs secrete suppressive cytokines, including IL-10, TGF- $\beta$, and IL-35. As previously described, TGF- $\beta$ plays a critical role in the 


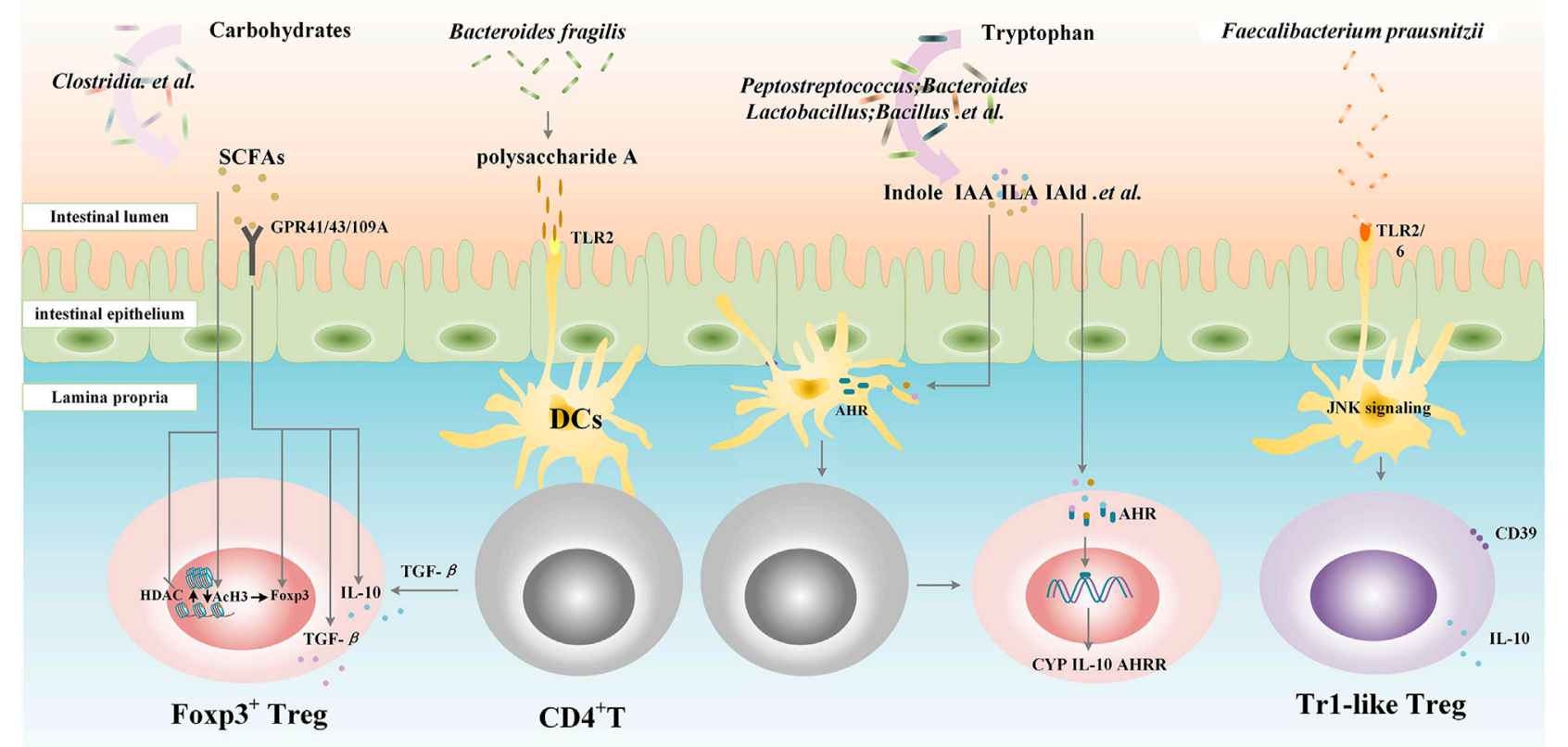

FIGURE 1 | Gut microbiota contributes to the differentiation and function of Tregs. Clostridia metabolize carbohydrates into short-chain fatty acids (SCFAs), which increase Treg numbers, Foxp3 expression, and the suppressive function of Foxp3+Tregs in a histone deacetylases (HDACs)/histone H3 acetylation (AcH3)-dependent manner. SCFAs also induce the differentiation of Tregs and Tr1 cells by increasing the expression of Foxp3 and upregulating the secretion of IL-10 and TGF- $\beta$ via G protein-coupled receptor (GPR) 41, GPCR43 and GPCR109A. Bacteroides fragilis exports polysaccharide A (PSA), through a toll-like receptor (TLR) 2; PSA is presented to naive $\mathrm{CD} 4^{+} \mathrm{T}$ cells by dendritic cells (DCs) in lamina propria followed by the activation of TGF- $\beta$-induced Foxp3 ${ }^{+}$Tregs to facilitate the secretion of IL-10 and promote immunologic tolerance. Bacteroides, Bifidobacterium, Clostridium, Peptostreptococcus, and Lactobacillus. metabolize tryptophan into indole and indole derivatives including tryptamine, indole-3-acetic acid (IAA), indole-3-aldehyde (IAld), and indole lactic acid (ILA), which can activate the aryl hydrocarbon receptor (AHR) translocating to the nucleus and initiating gene transcription (CYP family, IL-10, and AhRR) to enhance the immunosuppressive function of Tregs. Furthermore, the AhR also promotes $\mathrm{CD}_{4}^{+}$cells to differentiate into Tregs by interacting with DCs. Clostridium Faecalibacterium prausnitzii skews human DCs to prime Tr1-like Tregs by TLR2/ 6 triggering, C-Jun N-terminal kinase (JNK) signaling, and CD39 ectonucleotidase activity. SCFAs, short-chain fatty acids; GPR, G protein-coupled receptor; HDACs, histone deacetylases; AcH3, histone H3 acetylation; TLR, toll-like receptor; DCs, dendritic cells; IAA, indole-3-acetic acid; ILA, indole lactic acid; IAld, indole-3-aldehyde; AHR, aryl hydrocarbon receptor; CYP, cytochrome P450; AHRR, AHR repressor; JNK, c-Jun N-terminal kinase; Tr1, T regulatory type-1 cells.

induction of Tregs both in vivo and in vitro, while the contribution of TGF- $\beta$ to the suppressive capacity of Tregs remains controversial. A mount of studies using humans, mice, or cultured cells have failed to illustrate that TGF- $\beta$, either in the membrane-bound or soluble form, is essential for Treg-mediated suppression (Piccirillo et al., 2002; Kullberg et al., 2005; Oberle et al., 2007). In contrast, mice without T-cell-specific TGF- $\beta$ production or processing develop an autoimmune syndrome (Li et al., 2007). In addition, Nakamura K. et al. suggested that membrane-type TGF$\beta$-mediated suppression may inhibit Teffs by binding to the TGF- $\beta$ receptor on the Teff surface, and Hui X. et al. observed that triptolide restrains OCs differentiation and bone resorption in vitro through IL- 10 and TGF- $\beta 1$ production by Tregs (Xu et al., 2016). Thus, we proposed that the role of TGF- $\beta$ in Tregmediated suppression may depend on the type of Teffs and the site of the immune response in a cell contact-dependent manner (Andersson et al., 2008). IL-10 production by Tregs is essential for restraining immune responses, such as those in the bone and those involved in mucosal homeostasis (Li et al., 2016a). For instance, Asseman C. et al. illustrated that colitogenic Th1 cells are suppressed by $\mathrm{CD} 4^{+} \mathrm{CD} 25^{+}$Tregs in an IL-10-dependent manner in mice (Asseman and Powire, 1998). Furthermore, an anti-CTLA- $4 \mathrm{mAb}$ induces high levels of IL-10 secretion by Tregs and high expression of inducible co-stimulator (ICOS) on Tregs, and this treatment inhibits Th1 memory responses and represses experimental intestinal inflammation in a mouse model of colitis (Coquerelle et al., 2009). In APCs, IL-10 suppresses the production of pro-inflammatory cytokines, chemokines, and chemokine receptors, as well as the expression of major histocompatibility complex (MHC) class II and CD80/ CD86 co-stimulatory molecules (Akdis and Akdis, 2014). Another cytokine, IL-35, contributes to the function of Tregs by directly affecting responder $\mathrm{T}$ cells such as $\mathrm{T}$ helper cells 1 (Th1) and 17(Th17), which likely affects DCs (Song and Ma, 2016).

\section{Induction of Apoptosis}

Granzyme A, granzyme B, and perforin are three of the key components of Treg-induced suppression mediated through the induction of apoptosis in a cell-cell contact manner (Gondek et al., 2005). Tregs mediate cytotoxicity-induced cell death through the CD95 death receptor and caspase 3 in multiple cell types, including $\mathrm{CD}^{+} \mathrm{T}$ cells, $\mathrm{CD}^{+} \mathrm{T}$ cells, $\mathrm{CD} 14^{+}$ 
monocytes, NK cells, and DCs, in humans (Grossman et al., 2004; Ataera et al., 2013). In addition, galectin-1, which is secreted by Tregs, binds to glycoproteins (CD45, CD43, and CD7), resulting in cell cycle arrest and apoptosis in responder cells (Garin et al., 2007). The other mechanism is related to IL-2, and this mechanism is controversial. Some groups have demonstrated that the consumption of IL- 2 by Tregs induces apoptosis in effector cells in mice (Pandiyan et al., 2007). However, Oberle did not observe the induction of apoptosis in Tconvs by Tregs in humans (Oberle et al., 2007). More recent studies have shown that Tregs suppress $\mathrm{CD} 8^{+} \mathrm{T}$-cell responses via $\mathrm{IL}-2$ depletion and that IL-2 plays an indispensable role in mice (Vercoulen et al., 2009). Based on the findings above, it is thought that the consumption of IL- 2 by Tregs diminishes the IL-2 pool that is indispensable for Teffs, resulting in restricted expansion and even leading to apoptosis. Additionally, other studies have reported that IL-2 contributes to the development of the suppressive function of Tregs through calcium signaling to $\mathrm{T}$ and $\mathrm{NK}$ cells in patients (Whitehouse et al., 2017). Thus, we speculate that IL2 activates multiple signaling pathways to suppress functions and/or induce apoptosis in target cells and that differences are likely due to cell types.

\section{Disruption of Metabolic Processes}

Tregs disrupt metabolic processes in target cells. One mechanism is mediated through the CD39/CD73 expression, and it results in the metabolism of adenosine triphosphate (ATP) to adenosine $5^{\prime}$-monophosphate (AMP) and the production of adenosine, which binds to the adenosine $\mathrm{A} 2 \mathrm{~A}$ receptor, followed by an increase in the intracellular cyclic adenosine 3, $5^{\prime}$-monophosphate (cAMP) level in target cells (Tconvs and DCs) (Borsellino et al., 2007; Ohta and Sitkovsky, 2014). Subsequently, the protein kinase A (PKA) pathway and the noncanonical cAMP pathway are activated, resulting in immunosuppression.

\section{Decreased Costimulation and Antigen Presentation by APCs}

Tregs decrease costimulation and antigen presentation by regulating the cell contact-dependent modulation of APCs. CTLA-4, which is located on the surface and in the submembrane vesicles of Tregs, is also detected in Golgi vesicles of Tconvs at rest and released after the stimulation of the TCR (Tai et al., 2012). The molecular mechanism of Tregmediated suppression via CTLA-4 is clear in relative terms. For APCs, particularly DCs, CTLA- 4 competes with the CD28 costimulatory molecule for binding to the CD80/CD86 molecules to induce cell cycle arrest (Chikuma, 2017). Furthermore, CTLA-4 downregulates the CD80/CD86 expression on APCs through trans-endocytosis to directly suppress Tconvs in vitro and in vivo (Qureshi et al., 2011). In addition, Tregs facilitate the DC expression of IDO via CTLA-4, which converts tryptophan to kynurenine in Teffs, and this change also leads directly to cell cycle arrest and reduced glutathione synthesis, resulting in a redox environment detrimental to Tconv proliferation (Yan et al.,
2010). Furthermore, an increased IDO expression promotes iTreg generation (Curran et al., 2014). A recent report has illustrated that Tregs suppress autophagy in DCs via CTLA-4-mediated activation of the PI3K/Akt/mTOR axis and FoxO1 nuclear exclusion, subsequently leading to decreased transcription of the autophagy component, microtubule-associated protein 1 light chain $3 \beta$ (Alissafi et al., 2017). Lymphocyte activation gene (LAG)-3 (CD223), a CD4 homolog that binds to MHC class II on immature DCs, induces immunoreceptor tyrosinebased activation motifs (ITAM)-mediated inhibition to suppress the development and antigen presentation capacity of DCs (Liang et al., 2008).

\section{TREGS IN RA}

\section{Mechanisms of Abnormal Treg Level Level of Tregs in RA}

The proportion of Tregs in the peripheral blood of patients with RA is controversial. Some studies have shown that RA patients have lower or higher frequencies of $\mathrm{CD} 4^{+} \mathrm{CD} 25^{+} \mathrm{Foxp} 3^{+}$Tregs or $\mathrm{CD} 4^{+} \mathrm{CD} 25^{+} \mathrm{CD} 127^{-}$Tregs in the peripheral blood than healthy subjects (van Roon et al., 2010; Vitales-Noyola et al., 2018). Other researchers have found that the level of peripheral $\mathrm{CD} 4^{+} \mathrm{CD} 25^{+}{ }^{+}$oxp $3^{+}$Tregs in RA patients is almost the same as that of healthy people (Tang et al., 2011). Based on the existing cognitive status of RA immunity, the number of Tregs should be decreased in RA. As shown in Supplementary Table 1, a review of the literature from the past 10 years indicates that most studies do report that the level of peripheral Tregs is decreased in RA patients.

Based on our review, there are several reasons leading to the different Treg results. 1) Different markers lead to different ratios. Although $\mathrm{CD} 4^{+} \mathrm{CD} 25^{+} \mathrm{Foxp}^{+}$cells are thought to be the underlying Tregs, markers of Tregs remain controversial, and researchers may use different markers for different purposes. For example, Yang $\mathrm{M}$ et al. not only studied the proportion of $\mathrm{CD} 4^{+} \mathrm{CD} 25^{+} \mathrm{CD} 127^{\text {low/ }}$ foxp $3^{+}$Tregs but also observed $\quad \mathrm{CD} 4^{+} \mathrm{CD} 25^{+} \mathrm{CD} 127^{\text {low } /-}$ Foxp $3^{+}$Helios ${ }^{+}$Tregs, $\mathrm{CD} 4^{+} \mathrm{CD} 25^{+} \mathrm{CD} 127^{\text {low/- }}$ Foxp $^{+} \mathrm{CD} 226^{+}$Tregs, and $\mathrm{CD}^{+} \mathrm{CD} 25^{+} \mathrm{CD} 127^{\text {low } /-}{ }^{-}$Foxp $^{+}{ }^{+}$TIGIT $^{+}$Tregs in the same study and obtained different results (Yang et al., 2019). 2) Similarly, different Treg phenotypes have different proportions in RA. Altered Tregs may be just one of the phenotypes of Tregs, while the other phenotypes remain unchanged. For example, a previous study has shown that the aTregs $\left(\mathrm{CD} 4{ }^{+} \mathrm{CD} 25^{+++} \mathrm{CD} 45 \mathrm{RA}^{-}\right)$and not the rTregs $\left(\mathrm{CD} 4{ }^{+} \mathrm{CD} 25^{++} \mathrm{CD} 45 \mathrm{RA}^{+}\right)$contribute to the decrement of total Tregs in the peripheral blood of RA (Kim et al., 2012). 3) The percentage of Tregs may be related to the disease state. Compared to the remission stage, the active stage of the disease is mainly characterized by intense inflammatory activity and causes more abnormal immune status. Wu et al. studied this point and found that the proportion and function of peripheral blood Tregs in remission RA are almost the same as in the normal control, but that the proportion and function represented by IL-10 Tregs are decreased in active RA (Wu 
et al., 2016). 4) Furthermore, the different results may be related to the duration. Barbera et al. reported that unchanged Tregs are present in early RA (Barbera et al., 2016). Another study has found that patients with a mean (range) RA duration of 15.2 (2-79) months now show a difference in peripheral blood Tregs compared to the control but that patients with a mean (range) disease duration of 123.7 (13-300) months have significantly lower peripheral blood Tregs than the control group. 5) In addition, the age of RA patients included in the study may contribute to the difference in the Treg status. Pawłowska J. et al. researched the relationship of age of RA onset with status of $\mathrm{T}$ cells and found that older age of RA onset is associated with a higher level and the activation status of peripheral blood $\mathrm{CD} 4^{+} \mathrm{T}$ cells, including Tregs and disease activity (Pawlowska et al., 2011).

In the study of Tregs, surface molecular markers are a common method for the classification of Tregs, but they may be deviant due to the influence of reagents and operating procedures. The search for new markers, such as specific miRNA expression, may resolve the confusion of markers to a certain extent. Furthermore, the age, disease course, and disease status of patients should be fully evaluated when RA patients are included.

\section{Molecular Mechanisms of Abnormal Treg Level}

RA patients maintain a continuous inflammatory state, and inflammatory factors such as IL-6, TNF- $\alpha$, and IL- $1 \beta$ are significantly increased. The persistent inflammatory state inhibits Treg formation and Foxp3 expression. Studies have shown that the levels of Tregs and IL-6 in peripheral blood mononuclear cell (PMBC) are negatively correlated (Khoshmirsafa et al., 2018). In addition, the activated NF- $\kappa B$ pathway by inflammatory environment can drive miR34a-impairing Treg/Th17 balance via targeting Foxp3 (Xie et al., 2019).

The level of exosomes in peripheral blood is changed in RA patients, and altered exosomes selectively affect Tregs. Wang et al. found that several miRNAs in the exosomes from RA peripheral blood were more abundant than those from healthy control donors. In upregulated miRNAs in RA patients, miR-17 inhibits induction of Tregs and reduces the number of Tregs by inhibiting the expression of TGF receptor II (TGFBR II) (Wang et al., 2018).

In addition, the abnormal number of Tregs is also caused by abnormal intestinal flora. As previously described, much bacteria produce metabolites that activate AhR, which plays an important role in the de novo production of Tregs. AhR expression is low on Tregs in RA, and Treg level can be significantly increased by activating the AhR pathway. A number of studies have shown that the abundance of bacteria that produce AhR ligands decreases in RA, and the activity of the AhR pathway in Tregs also decreases. By improving the colony structure of intestinal flora, the abundance of bacteria that metabolizes AhR ligands can be called back, followed by the increasing activity of the AhR signaling pathway, and upregulating the number of Tregs ( $\mathrm{Li}$ X. et al., 2020). Besides, other cells involved in Treg generation, such as DCs and B cells, are abnormal in RA, which results in impaired Treg formation justifiably (Moore et al., 2010).

\section{Mechanisms of Impaired Function of Tregs Unique Function of Tregs in RA}

Interaction with Th17. The balance between Tregs and Th17 is the key point in the maintenance of immune homeostasis. Similarities to that of other ADs, such as systemic lupus erythematosus and autoimmune hepatitis, the pathogenesis of RA has been observed to involve an imbalance between Tregs and Th17 (Jin et al., 2021). The inflammatory cytokine environment is a key driver that could globally push Tregs/Th17 toward imbalance because the combination of TGF- $\beta$ and IL- 6 allows T-cell differentiation toward the Th17 phenotype, whereas if TGF- $\beta$ is present alone, $\mathrm{T}$ cells will differentiate or revert into iTregs in vitro (Bettelli et al., 2006). Further research has shown that bacterial metabolites, dietary ligands of AhR, have immunomodulatory effects of differentiation of Tregs and Th17 in multiple ADs including RA (Yuan et al., 2016). In addition, our group also found that by activating the AhR signal, the human umbilical mesenchymal stem cells (HUMSCs) display therapeutic potential in RA by regulating immune imbalance dominated by Tregs and Th17 (Li M. et al., 2020). Further study found that AhR activation also decreases Th17 cytokines and increases IL-10 expression (Kim et al., 2019).

Involved in bone immunity. In addition to the function of immunosuppression, Tregs also show other functions specific to the disease characteristics of RA. Tregs play an important role in alleviating cartilage damage and bone destruction in RA. As a characteristic secondary disease, osteoporosis is common in RA patients. Cartilage damage and bone destruction in RA are partly caused by the activation of OCs. Previous studies have implied that Tregs suppress OC differentiation and bone resorption by regulating IL-10, TGF- $\beta 1$, and IL-4 (Xu et al., 2016). Furthermore, a previous report had shown that in addition to IL-10, TGF- $\beta 1$, and IL-4, CD80/86-deficient OCs cannot be inhibited by CTLA- 4 or Tregs, suggesting that CTLA- 4 and CD80/86 effectively inhibit OCs by inducing IDO/tryptophan (Bozec et al., 2014). Among them, the metabolites from the IDO/ tryptophan pathway are the main endogenous ligands in regulating AhR (Kumar et al., 2017). Based on this, it is speculated that AhR is the signaling pathway in Treg-regulated bone immunity. Based on the OC-Treg co-culture system in vitro, our previous research found that Tregs inhibit OC differentiation and bone resorption in a quantity-dependent manner, and triptolide enhanced the bone immunity function of Tregs via producing the IL-10 and TGF- $\beta 1$ (Xu et al., 2016). HUMSCs alleviate the destruction of bones in vivo by shifting Th1 cells toward the Th2 phenotype, inducing Tregs and increasing the expression of IL- 10 and TGF- $\beta 1$ in a collagen-induced arthritis (CIA) model (Li X. et al., 2020).

\section{Symptoms of Functional Impairment of Tregs}

Obviously, the function of Tregs plays an important role in the prognosis and deterioration of RA. Among the studies that have researched the immunosuppressive function of Tregs, however, 
most studies found that the function of Tregs is reduced as indicated in Supplementary Table 1.

The function of Tregs is impaired in many ways. Numerous studies have shown that Tregs derived from RA patients have a decreased ability to inhibit the proliferation and inflammatory factor secretion from Teffs (van Roon et al., 2010; Cribbs et al., 2015). Another study has found significant reductions in Treg secretion of IL-10 and TGF- $\beta 1$ in RA patients (Hashemi et al., 2018). Furthermore, studies have shown that Treg apoptosis in RA patients is increased and that Tregs are uncontrolled due to B-cell apoptosis mediated by Fas in RA (Li et al., 2014; Rapetti et al., 2015). In addition, the reduced function of Tregs may also be reflected in the reduced ability to interfere with the metabolic processes of target cells. As previously explained, one way in which Tregs play an inhibitory role is through the disruption of metabolic pathways, and CD35/CD27 is an important molecule on the surface of Tregs. One study has found that the expression of CD39 and CD73 is decreased in Tregs from RA patients (Zhang et al., 2019). CTLA-4 expression is also downregulated in Tregs from RA patients (Aldridge et al., 2021), which results in decreased co-stimulation and antigen presentation, indicating that the CTLA-4-mediated cell cycle arrest of APCs by Tregs is also weakened.

\section{Molecular Mechanisms of Tregs Impaired in RA}

Further studies have revealed the mechanisms that how Tregs are impaired. Similar with the abnormal levels of Tregs in RA, long-term inflammatory environment interferes with the immunosuppressive function of Tregs. Especially, high concentrations of TNF- $\alpha$ in RA patients appear to interfere with the suppressive function of Tregs (Farrugia and Baron, 2016). This evidence supports the excellent efficacy of TNF- $\alpha$ inhibitors for RA. Besides, in an inflammatory environment, Teffs are resistant to Tregs (Walter et al., 2016), which also exacerbates the immune imbalance.

An abnormal Foxp3 gene expression is also an important factor for abnormal Treg function. Hashemi et al. found that polymorphism of the Foxp3 gene affects the frequency and function of Tregs in RA patients, and RA patients with the AA genotype have lower frequencies of Tregs, and levels of TGF- $\beta$ and IL-10 than patients with CC and CA genotypes (Hashemi et al., 2018). Kennedy A. et al. identified a novel differentially methylated region (DMR) in upstream of the Foxp3 promoter, which exhibits dysregulated methylation in RA Tregs. Cribbs AP. et al. further proved that demethylation of the Foxp3 upstream enhancer restores Treg function in RA patients (Cribbs et al., 2015). In addition, phosphorylation of Foxp3 controls the function of Tregs, which can be inhibited by TNF- $\alpha$ in RA (Salomon, 2021). Besides, Su Q. et al. found the development of Tregs in RA was related to impaired Tip60mediated Foxp3 acetylation (Su et al., 2019).

Besides, an inadequate expression of cell surface molecules and failure to produce the soluble factors induce dysfunction of Tregs. The decreased expression of CTLA-4 in Tregs of RA is compromised by CTLA-4 promoter methylation, resulting in a failure to activate the indoleamine 2,3-dioxygenase pathway (Cribbs et al., 2014). Therefore, CTLA-4-Ig therapy enhances the function of Tregs in patients with RA.
Moreover, phenotypic change in Tregs is common in RA patients. A previous study has reported that a higher frequency of IL-17-producing Tregs is present in the peripheral blood of RA patients than in healthy subjects (Wang et al., 2015). In addition, an increased number of senescent Tregs in RA patients also contributes to the decreased function of Tregs (Fessler et al., 2017).

In the mechanism study of Tregs in RA, most researchers focus on how Tregs work, while few scholars focus on what influences Tregs' work. We think understanding why impaired function of Tregs in RA is better for restoring RA's immune homeostasis.

\section{Treg-Based Strategies for RA}

In consideration of the powerful immunosuppressive function of Tregs, Treg-based therapies become one of the major directions in RA treatment, and several therapeutic strategies have been explored. Although population heterogeneity and instability impact the curative effects of Treg-based strategies, these approaches have had a significant positive impact on the recovery of RA patients in recent years.

\section{Conventional Drug Therapy}

DMARD. To the best of our knowledge, there are no specific Tregtargeted chemical drugs or herbal medicines being used in the clinic or basic research, but many drugs show a beneficial effect on Treg levels and function. Methotrexate, a traditional DMARD, is one of the gold standards of therapy for RA that restores defective Treg function through demethylation of the Foxp3 locus, leading to subsequent facilitates in Foxp3 and CTLA-4 expression (Cribbs et al., 2015). Other widely used DMARDs, both leflunomide and sulfasalazine, inhibit the antiproliferative function of Tregs on cocultured Teffs, and they reduce the Treg expression of Foxp3 mRNA in PBMCs from healthy adults (Oh et al., 2013), and leflunomide can increase Treg cells but reduce Th17 in PBMC via activating AhR (Baban et al., 2012). In addition, iguratimod, an approved drug in the treatment of RA, downregulates the Th1/ Th17-type response and upregulates Tregs. At the same time, associated cytokines and transcription factors are also changed in a similar trend (Xu et al., 2015).

Biologicals. As more and more mechanisms are studied, biological therapies targeting to Treg number, function, and differentiation are being utilized to treat RA. TNF- $\alpha$ impairs the differentiation and function of TGF- $\beta$-induced Tregs in RA through the Akt and Smad3 signaling pathways, and the specific TNF- $\alpha$ inhibitor, infliximab, has been reported to increase the number of peripheral Tregs, especially through the generation of TGF- $\beta$-induced Tregs in RA patients (Salomon, 2021). Furthermore, TGF- $\beta$-induced Tregs are completely resistant to Th17 by IL- 6 conversion and maintained the immunosuppressive effect, while tTregs lost most of their cellular function, indicating that the dysregulation of IL-6 plays an important role in Treg function (Niu et al., 2018). Tocilizumab, an anti-IL-6R antibody, has become a strong and effective therapy for RA by regulating the proportion of Tregs in the PBMC population (Li et al., 2016b). Moreover, numerous studies have shown that a low dose IL-2 promotes balance among the Th1, Th17, and Treg distributions in patients with progressive RA (Kosmaczewska et al., 2015). Interestingly, IL-2 not only promotes naive $\mathrm{CD}^{+}$T-cell 
conversion into Tregs but also drives the differentiation to Teffs. The dominant cell type impacted depends on the dose of IL-2 because Tregs require 10-20 times less IL-2 than Teffs at the p-STAT level and 100-fold less at genetic transcription levels. Therefore, whether IL-2 has a positive or negative impact on RA depends on the IL-2 concentration (Klatzmann and Abbas, 2015). Additionally, CTLA-4-Ig therapy enhances the function of Tregs in patients with RA (Alvarez-Quiroga et al., 2011).

Although biologics have pitfalls, they are promising. The development of biological agents with multiple targets, low side effects, and high reactivity is imminent.

\section{Traditional Chinese Medicines}

Although conventional drugs have been relatively systematic and effective, these drugs are reported to have varying degrees of side effects, such as gastrointestinal disorders, immunodeficiency, infection, and humoral disturbances. Exploring new therapeutic agents with low toxicity and high efficacy is strongly needed in the treatment of RA. Complementary therapies based on TCM can be recommended as complementary and alternative.

Formula. The traditional Chinese medicine formula focuses on individual treatment, which is based on the guidance of traditional Chinese medicine theory and compatible with different Chinese herbs. The traditional Chinese medicine formula plays a multi-target therapeutic role by regulating the system state of the human body, with definite curative effect and low side effect. Traditional Chinese medicine formula plays an indispensable role in the treatment of RA in China. Yi Shen Juan Bi Pill, a traditional Chinese medicine formula widely used in clinics, has powerful regulatory effects in CIA rats via regulating Tregs (Zhao et al., 2018; Peng et al., 2019). Another decoction named Qianghuo Erhuang can significantly decrease the disease activity score in 28 joints (DAS28), erythrocyte sedimentation rate (ESR), and C-reactive protein (CRP) in RA and upregulate the percentage of Tregs in adjuvantinduced arthritis in rats (Qian et al., 2017). Besides, Er Miao San attenuates rat's arthritis by regulating Th17/Tregs (Dai et al., 2020).

Extract. Other drugs, especially Chinese herbal extracts, also have the potential to regulate Tregs in experimental studies. Among these, total glucosides of paeony, from Radix Paeoniae Alba, dynamically regulate gut microbiota, suggesting that the regulatory role of Tregs is related to the change of intestinal flora. Tripterygium wilfordii glycosides, extracted from Tripterygium wilfordii Hook.f., demonstrate great improvement in RA disease activity and immunosuppressive via Tregs (Luo et al., 2019). In addition, ethanolic extract of the Saussurea lappa (costus) root and water extract of the Saussurea involucrata (Kar. et Kir.) Sch.Bip. have potential anti-arthritic activity and improves the immune responses of adjuvant-induced monoarthritis in rats (Han et al., 2016; Tag et al., 2016).

Natural compound from TCM. One study has reported that oxymatrine significantly reduces the production of TNF- $\alpha$ and IL17A but upregulates Foxp3 expression in CIA rats (Ma et al., 2017). In addition, periplocoside $\mathrm{A}$ increases the proportion of Tregs among helper $\mathrm{T}$ cells and inhibits the differentiation and reactivity of $\mathrm{h}$ in CIA mice (Yang et al., 2017). Grape seed proanthocyanidin has proven potent anti-arthritic effects on CIA by inducing Th17/Treg rebalance (Ahmad et al., 2013). Dioscin, extracted from Dioscorea nipponica Makino, affects the differentiation of Tregs, secretion of related factors, and the expression of STAT3 and STAT5 in CIA mice (Xing et al., 2019). In the gut lymphoid tissues of sinomenine-treated rats, the frequency of Tregs is facilitated, and the frequency of Th17 is decreased (Wang et al., 2013). Based on this study, it is speculated that the regulatory effect of sinomenine on Tregs may be related to intestinal flora. The percentage of $\mathrm{AhR}^{+}$cells in $\mathrm{CD} 4^{+} \mathrm{CD} 25^{+} \mathrm{T}$ cells has been proven to be significantly lower in RA patients than in controls (Cheng et al., 2017). As a ligand of the AhR, tetrandrine and flavonoid naringenin mediate Tregs through the AhR pathway (Wang W. et al., 2012; Yuan et al., 2016).

The curative effect of TCM is great, but due to the complex composition, unclear mechanism, a small part of traditional Chinese medicine with side effects, and other reasons, TCM's recognition is limited. In addition, the use of traditional Chinese medicine needs the guidance of the basic theory of traditional Chinese medicine, which also limits the wide application of them.

\section{Bacteria-Based Therapy}

Specific alterations are observed in the gut and oral microbiomes in RA individuals and CIA models. Furthermore, studies have been done to demonstrate the influence of flora on RA by administering pathogenic bacteria Porhyromonas gingivalis that can aggravate rheumatoid arthritis (Sato et al., 2017). Consequently, it is hoped that changes in intestinal flora in a certain direction might be effective in RA treatment. Currently, there are roughly two therapeutic methods for affecting gut microbiomes.

One is to observe the changes of gut microbiomes in RA or animal models through agent intervention, such as total glucosides of paeony and HUMSCs. This method cannot completely prove that the efficacy is caused by the change of flora because it is possible that the host immune state is change first, followed by the change of gut microbiomes affected under the host intestinal mucosal immunity.

Another is microbiota transplantation. There are also two types of microflora transplantation, which are as follows: one is oral prebiotics and probiotics or a combination of the two synbiotics, and the other one is fecal microbiota transplantation (FMT). Supplementation of synbiotics had beneficial effects among patients with RA. And supplementation of probiotics, such as Lactobacillus casei, decreases disease activity and increases the release of IL-10 of RA as reported in a randomized double-blind clinical trial (Alipour et al., 2014). In addition, Lactobacillus salivarius and Lactobacillus plantarum isolated from RA patients increase Treg frequency, and decrease arthritis scores, synovial infiltration, and bone erosion in CIA mice (Liu et al., 2016). In addition, synbiotics, PSA, derived from the human commensal Bacteroides fragilis can stimulate immunologic development, which can increase suppressive function and promote differentiation of Tregs (Telesford et al., 2015). Furthermore, heat-killed Lactobacillus reuteri alleviate the severity and the prevalence of CIA by increasing the frequency of Tregs and $\mathrm{CD} 4^{+} \mathrm{IL}-10^{+}$cells, which means the probiotic supplementation can not only treat the RA but also prevent the RA (Yokota et al., 2018). As for FMT, the rise of FMT is due to its excellent efficacy 
in the treatment of Clostridium difficile infection, and its subsequent efficacy is shown in other inflammatory diseases such as inflammatory bowel disease and pseudomembranous enteritis with unknown pathogen infection. Up to now, there is no report on the efficacy of FMT in RA. The closest study is a 6month, double-blind, randomized, placebo-controlled trial in patients with psoriatic arthritis (Kragsnaes et al., 2018). Despite the risks of FMT, its immunomodulatory effects in RA should be fully exploited.

Studies on microflora focus on intestinal microflora, but oral microflora and ectopic microflora should also be investigated. In addition, there is no research on RA treatment by FMT, which may be a new direction for the development of RA therapy.

\section{Cell Transfer Therapy}

Given its fewer side effects and potential efficacy, cell transfer therapy is being considered the epoch of a new generation of therapy for treating a multitude of diseases, including RA, distinct from the era of treatment with pharmacological agents. Although the curative effect of Treg transfer is limited under some conditions, several studies have revealed that Treg transfer prevents the progression of RA (Niu et al., 2018). After supplementation with chemical reagents to modify Treg signaling pathways or biological agents for genetic modification, the purity, yield, specificity, and safety of Treg treatments are enhanced (Milward et al., 2017). Except for a few clinical studies, the Treg transfer therapy is mostly in the stage of animal studies. It is worth mentioning that this therapy has been successful in CIA. After transferring Tregs into immunocompetent CIA mice, disease progression is slowed, and Tregs are found in the inflamed synovium soon after transfer (Morgan et al., 2005). Beyond transferred Tregs, stem cell transplantation shows an immunoregulatory capability during the progression of RAs based on the Treg function. Specifically, the use of HUMSCs has shown promising results relating to a significant increase in Treg percentage in clinical trials even in severe and resistant RA patients (Ghoryani et al., 2019). Our previous study has also suggested that HUMSCs alleviate CIA partly by regulating Tregs and Th17 (Li M. et al., 2020).

Cell transfer therapy appears to be safe and well tolerated, but the challenge is to obtain stable function and a substantial number of Tregs that are of controlled quality.

\section{Target-Based Therapy}

The most successful example of target-based therapy is tofacitinib (CP-690,550), which is a blockbuster drug affected in patients with moderately to severely active RA who have had an inadequate response or intolerance to methotrexate. Tofacitinib is a selective Janus kinase (JAK) inhibitor that preferentially inhibits JAK1 and JAK3. Cytokine binding to receptor of JAKs activates JAKs, which phosphorylates signal transducers and activators of transcription (STATs). Then, JAKs and STATs dimerize and translocate to nucleus where they regulate gene transcription (Ptacek et al., 2021). By blocking interferon (IFN) and IL-6, tofacitinib can decrease synovial immune and inflammatory responses (Boyle et al., 2015). At a clinically relevant dose, tofacitinib effectively preserves the suppressive activity of $\mathrm{CD} 4{ }^{+} \mathrm{CD} 25^{\text {bright }}$ Tregs but inhibits Teff functions by suppressing IL-2-induced P-STAT activity (Sewgobind et al., 2010).

Furthermore, as a key target connecting host immunity and intestinal flora as described above, AhR might be an effective target for regulating both immune status and intestinal flora. In another autoimmune disease, AhR agonists have been effective in plaque psoriasis on a Phase 2, randomized dose-finding study (Robbins et al., 2019). The result suggests the potential of AhR agonists in the treatment of RA.

\section{SUMMARY AND FUTURE PERSPECTIVES}

Although there is a considerable amount of knowledge about Tregs, continuous and repeated courses of RA with high disability rates are still occurring. Most studies on Tregs mainly focus on the number/proportion and associated cytokines, but the immunosuppressive mechanism of Tregs is much more complicated and study worthy. A previous study has made it clear that the pathogenesis of RA and prognosis are related to genetic and environmental factors. The curative effect of drugs on the individual differences in the corresponding relationship with a genotype is helpful to guide the choice of drugs and accurate medicinal development. However, few studies have focused on drug research based on genotype. In addition, several researchers are studying the effects of environmental pollutants, namely, polycyclic aromatic hydrocarbons, and their receptor AhR on RA and Tregs. Fortunately, tapinarof may have potential to treat RA (Bissonnette et al., 2021). Although single-target therapy for single molecules and single proteins is effective, the efficacy is limited. Individualized and system-based treatments should be a greater focus. A rational application of TCM, precise treatment based on genotype, and bacteria-based therapy may be the future of RA treatment.

\section{AUTHOR CONTRIBUTIONS}

XLi, HX, DL, and SL wrote the manuscript; XLu and JH generated the figures; and CX revised the manuscript.

\section{FUNDING}

This work was supported by the National Natural Science Foundation of China (grant number 82073677).

\section{SUPPLEMENTARY MATERIAL}

The Supplementary Material for this article can be found online at: https://www.frontiersin.org/articles/10.3389/fphar.2021.716081/ full\#supplementary-material 


\section{REFERENCES}

Ahmad, S. F., Zoheir, K. M., Abdel-Hamied, H. E., Ashour, A. E., Bakheet, S. A., Attia, S. M., et al. (2013). Grape Seed Proanthocyanidin Extract Has Potent Antiarthritic Effects on Collagen-Induced Arthritis by Modifying the T Cell Balance. Int. Immunopharmacol. 17 (1), 79-87. doi:10.1016/j.intimp.2013.05.026

Akdis, C. A., and Akdis, M. (2014). Mechanisms of Immune Tolerance to Allergens: Role of IL-10 and Tregs. J. Clin. Invest. 124 (11), 4678-4680. doi:10.1172/JCI78891

Alameddine, J., Godefroy, E., Papargyris, L., Sarrabayrouse, G., Tabiasco, J., Bridonneau, C., et al. (2019). Faecalibacterium Prausnitzii Skews Human DC to Prime IL10-Producing T Cells through TLR2/6/JNK Signaling and IL-10, IL-27, CD39, and Ido-1 Induction. Front. Immunol. 10, 143. doi:10.3389/ fimmu.2019.00143

Aldridge, J., Andersson, K., Gjertsson, I., Ekwall, A. H., Hallstråm, M., van Vollenhoven, R., et al. (2021). Blood PD-1+TFh and CTLA-4+CD4+ T Cells Predict Remission After CTLA-4Ig Treatment in Early Rheumatoid Arthritis. Rheumatology (Oxford). doi:10.1093/rheumatology/keab454

Alipour, B., Homayouni-Rad, A., Vaghef-Mehrabany, E., Sharif, S. K., VaghefMehrabany, L., Asghari-Jafarabadi, M., et al. (2014). Effects of Lactobacillus Casei Supplementation on Disease Activity and Inflammatory Cytokines in Rheumatoid Arthritis Patients: a Randomized Double-Blind Clinical Trial. Int. J. Rheum. Dis. 17 (5), 519-527. doi:10.1111/1756-185X.12333

Alissafi, T., Banos, A., Boon, L., Sparwasser, T., Ghigo, A., Wing, K., et al. (2017). Tregs Restrain Dendritic Cell Autophagy to Ameliorate Autoimmunity. J. Clin. Invest. 127 (7), 2789-2804. doi:10.1172/JCI92079

Alunno, A., Bartoloni, E., Nocentini, G., Bistoni, O., Ronchetti, S., Petrillo, M. G., et al. (2010). Role of Regulatory T Cells in Rheumatoid Arthritis: Facts and Hypothesis. Auto Immun. Highlights 1 (1), 45-51. doi:10.1007/s13317-0100008-2

Alvarez-Quiroga, C., Abud-Mendoza, C., Doniz-Padilla, L., Juarez-Reyes, A., Monsivais-Urenda, A., Baranda, L., et al. (2011). CTLA-4-Ig Therapy Diminishes the Frequency but Enhances the Function of Treg Cells in Patients with Rheumatoid Arthritis. J. Clin. Immunol. 31 (4), 588-595. doi:10.1007/s10875-011-9527-5

Andersson, J., Tran, D. Q., Pesu, M., Davidson, T. S., Ramsey, H., O'Shea, J. J., et al. (2008). CD4+ FoxP3+ Regulatory T Cells Confer Infectious Tolerance in a TGF-beta-dependent Manner. J. Exp. Med. 205 (9), 1975-1981. doi:10.1084/ jem. 20080308

Apetoh, L., Quintana, F. J., Pot, C., Joller, N., Xiao, S., Kumar, D., et al. (2010). The Aryl Hydrocarbon Receptor Interacts with C-Maf to Promote the Differentiation of Type 1 Regulatory T Cells Induced by IL-27. Nat. Immunol. 11 (9), 854-861. doi:10.1038/ni.1912

Arpaia, N., Campbell, C., Fan, X., Dikiy, S., van der Veeken, J., Deroos, P., et al. (2013). Metabolites Produced by Commensal Bacteria Promote Peripheral Regulatory T-Cell Generation. Nature 504 (7480), 451-455. doi:10.1038/ nature12726

Asseman, C., and Powrie, F. (1998). Interleukin 10 Is a Growth Factor for a Population of Regulatory T Cells. Gut 42 (2), 157-158. doi:10.1136/gut.42.2.157

Ataera, H., Simkins, H. M., Hyde, E., Yang, J., Hermans, I. F., Petersen, T. R., et al. (2013). The Control of CD8+ T Cell Responses Is Preserved in PerforinDeficient Mice and Released by Depletion of CD4+CD25+ Regulatory T Cells. J. Leukoc. Biol. 94 (4), 825-833. doi:10.1189/jlb.0413200

Avdeeva, A., Rubtsov, Y., Dyikanov, D., Popkova, T., and Nasonov, E. (2020). Regulatory T Cells in Patients with Early Untreated Rheumatoid Arthritis: Phenotypic Changes in the Course of Methotrexate Treatment. Biochimie 174, 9-17. doi:10.1016/j.biochi.2020.03.014

Baban, B., Liu, J. Y., and Mozaffari, M. S. (2012). Aryl Hydrocarbon Receptor Agonist, Leflunomide, Protects the Ischemic-Reperfused Kidney: Role of Tregs and Stem Cells. Am. J. Physiol. Regul. Integr. Comp. Physiol. 303 (11), R1136-R1146. doi:10.1152/ajpregu.00315.2012

Barbera, A., Lorenzo, N., van Kooten, P., van Roon, J., de Jager, W., Prada, D., et al. (2016). APL1, an Altered Peptide Ligand Derived from Human Heat-Shock Protein 60, Increases the Frequency of Tregs and its Suppressive Capacity against Antigen Responding Effector CD4 + T Cells from Rheumatoid Arthritis Patients. Cell Stress Chaperones 21 (4), 735-744. doi:10.1007/s12192-0160698-0
Bettelli, E., Carrier, Y., Gao, W., Korn, T., Strom, T. B., Oukka, M., et al. (2006). Reciprocal Developmental Pathways for the Generation of Pathogenic Effector TH17 and Regulatory T Cells. Nature 441 (7090), 235-238. doi:10.1038/ nature 04753

Bianchini, R., Bistoni, O., Alunno, A., Petrillo, M. G., Ronchetti, S., Sportoletti, P., et al. (2011). CD4(+) CD25(low) GITR (+) Cells: a Novel Human CD4(+) T-Cell Population with Regulatory Activity. Eur. J. Immunol. 41 (8), 2269-2278. doi:10.1002/eji.201040943

Bissonnette, R., Stein, G. L., Rubenstein, D. S., Tallman, A. M., and Armstrong, A. (2021). Tapinarof in the Treatment of Psoriasis: A Review of the Unique Mechanism of Action of a Novel Therapeutic Aryl Hydrocarbon Receptor-Modulating Agent. J. Am. Acad. Dermatol. 84 (4), 1059-1067. doi:10.1016/j.jaad.2020.10.085

Borsellino, G., Kleinewietfeld, M., Di Mitri, D., Sternjak, A., Diamantini, A., Giometto, R., et al. (2007). Expression of Ectonucleotidase CD39 by Foxp3+ Treg Cells: Hydrolysis of Extracellular ATP and Immune Suppression. Blood 110 (4), 1225-1232. doi:10.1182/blood-2006-12-064527

Boyle, D. L., Soma, K., Hodge, J., Kavanaugh, A., Mandel, D., Mease, P., et al. (2015). The JAK Inhibitor Tofacitinib Suppresses Synovial JAK1-STAT Signalling in Rheumatoid Arthritis. Ann. Rheum. Dis. 74 (6), 1311-1316. doi:10.1136/annrheumdis-2014-206028

Bozec, A., Zaiss, M. M., Kagwiria, R., Voll, R., Rauh, M., Chen, Z., et al. (2014). T Cell Costimulation Molecules CD80/86 Inhibit Osteoclast Differentiation by Inducing the Ido/tryptophan Pathway. Sci. Transl. Med. 6 (235), 235 ra60. doi:10.1126/scitranslmed.3007764

Carrier, Y., Whitters, M. J., Miyashiro, J. S., Labranche, T. P., Ramon, H. E., Benoit, S. E., et al. (2012). Enhanced GITR/GITRL Interactions Augment IL-27 Expression and Induce IL-10-producing Tr-1 like Cells. Eur. J. Immunol. 42 (6), 1393-1404. doi:10.1002/eji.201142162

Chai, J., Xue, S., Coe, D., Addey, C., Bartok, I., Scott, D., et al. (2005). Regulatory T Cells, Derived from Naive CD4+CD25-T Cells by In Vitro Foxp3 Gene Transfer, Can Induce Transplantation Tolerance. Transplantation 79 (10), 1310-1316. doi:10.1097/01.TP.0000159147.56408.9C

Chen, R., Tao, Y., Qiu, K., Huang, W., Huang, C., and Li, J. (2012). [Association of Circulating Treg Cells with Disease Activity in Patients with Rheumatoid Arthritis]. Nan Fang Yi Ke Da Xue Xue Bao 32 (6), 886-889.

Cheng, L., Qian, L., Tan, Y., Wang, G. S., Li, X. M., Li, X. P., et al. (2017). Unbalanced Expression of Aryl Hydrocarbon Receptor in Peripheral Blood CCR6(+)CD4(+) and CD4(+)CD25(+)T Cells of Rheumatoid Arthritis. Rev. Bras Reumatol Engl. Ed. 57 (3), 190-196. doi:10.1016/j.rbre.2016.07.002

Chiang, H. I., Li, J. R., Liu, C. C., Liu, P. Y., Chen, H. H., Chen, Y. M., et al. (2019). An Association of Gut Microbiota with Different Phenotypes in Chinese Patients with Rheumatoid Arthritis. J. Clin. Med. 8 (11), 1770. doi:10.3390/jcm8111770

Chikuma, S. (2017). CTLA-4, an Essential Immune-Checkpoint for T-Cell Activation. Curr. Top. Microbiol. Immunol. 10, 99-126. doi:10.1007/82_2017_61 Coquerelle, C., Oldenhove, G., Acolty, V., Denoeud, J., Vansanten, G., Verdebout, J. M., et al. (2009). Anti-CTLA-4 Treatment Induces IL-10-producing ICOS+ Regulatory T Cells Displaying Ido-dependent Anti-inflammatory Properties in a Mouse Model of Colitis. Gut 58 (10), 1363-1373. doi:10.1136/ gut.2008.162842

Cribbs, A. P., Kennedy, A., Penn, H., Amjadi, P., Green, P., Read, J. E., et al. (2015). Methotrexate Restores Regulatory T Cell Function through Demethylation of the FoxP3 Upstream Enhancer in Patients with Rheumatoid Arthritis. Arthritis Rheumatol. 67 (5), 1182-1192. doi:10.1002/art.39031

Cribbs, A. P., Kennedy, A., Penn, H., Read, J. E., Amjadi, P., Green, P., et al. (2014). Treg Cell Function in Rheumatoid Arthritis Is Compromised by Ctla-4 Promoter Methylation Resulting in a Failure to Activate the Indoleamine 2,3-dioxygenase Pathway. Arthritis Rheumatol. 66 (9), 2344-2354. doi:10.1002/art.38715

Curran, T. A., Jalili, R. B., Farrokhi, A., and Ghahary, A. (2014). Ido Expressing Fibroblasts Promote the Expansion of Antigen Specific Regulatory T Cells. Immunobiology 219 (1), 17-24. doi:10.1016/j.imbio.2013.06.008

Dai, X., Yang, D., Bao, J., Zhang, Q., J, D., Liu, M., et al. (2020). Er Miao San, a Traditional Chinese Herbal Formula, Attenuates Complete Freund's AdjuvantInduced Arthritis in Rats by Regulating Th17/Treg Cells. Pharm. Biol. 58 (1), 157-164. doi:10.1080/13880209.2020.1720745

Deane, K. D., and Holers, V. M. (2021). Rheumatoid Arthritis Pathogenesis, Prediction, and Prevention: An Emerging Paradigm Shift. Arthritis Rheumatol. 73 (2), 181-193. doi:10.1002/art.41417 
Denison, M. S., and Nagy, S. R. (2003). Activation of the Aryl Hydrocarbon Receptor by Structurally Diverse Exogenous and Endogenous Chemicals. Annu. Rev. Pharmacol. Toxicol. 43, 309-334. doi:10.1146/ annurev.pharmtox.43.100901.135828

Dulic, S., Vasarhelyi, Z., Sava, F., Berta, L., Szalay, B., Toldi, G., et al. (2017). T-cell Subsets in Rheumatoid Arthritis Patients on Long-Term Anti-TNF or IL-6 Receptor Blocker Therapy. Mediators Inflamm. 2017, 6894374. doi:10.1155/ 2017/6894374

Faber, E., Gripp, E., Maurischat, S., Kaspers, B., Tedin, K., Menz, S., et al. (2016). Novel Immunomodulatory Flagellin-like Protein FlaC in Campylobacter Jejuni and Other Campylobacterales. mSphere 1 (1), e00028-15. doi:10.1128/ mSphere.00028-15

Fahlen, L., Read, S., Gorelik, L., Hurst, S. D., Coffman, R. L., Flavell, R. A., et al. (2005). T Cells that Cannot Respond to TGF-Beta Escape Control by CD4(+) CD25(+) Regulatory T Cells. J. Exp. Med. 201 (5), 737-746. doi:10.1084/ jem.20040685

Farid, E., Mumtaz, M., Hajji, F., Ebrahim, R. A., Abdulla, H., and Tabbara, K. (2020). T Regulatory Cells in Rheumatoid Arthritis with Reference to Anticitrullinated Peptide Antibody and TNF-Alpha Inhibitor Therapy. Egypt. J. Immunol. 27 (1), 55-63.

Farrugia, M., and Baron, B. (2016). The Role of TNF- $\alpha$ in Rheumatoid Arthritis: a Focus on Regulatory T Cells. J. Clin. Transl Res. 2 (3), 84-90.

Fessler, J., Raicht, A., Husic, R., Ficjan, A., Schwarz, C., Duftner, C., et al. (2017). Novel Senescent Regulatory T-Cell Subset with Impaired Suppressive Function in Rheumatoid Arthritis. Front. Immunol. 8, 300. doi:10.3389/ fimmu.2017.00300

Fontenot, J. D., Gavin, M. A., and Rudensky, A. Y. (2003). Foxp3 Programs the Development and Function of CD4+CD25+ Regulatory T Cells. Nat. Immunol. 4 (4), 330-336. doi:10.1038/ni904

Furusawa, Y., Obata, Y., Fukuda, S., Endo, T. A., Nakato, G., Takahashi, D., et al. (2013). Commensal Microbe-Derived Butyrate Induces the Differentiation of Colonic Regulatory T Cells. Nature 504 (7480), 446-450. doi:10.1038/ nature12721

Gambineri, E., Torgerson, T. R., and Ochs, H. D. (2003). Immune Dysregulation, Polyendocrinopathy, Enteropathy, and X-Linked Inheritance (IPEX), a Syndrome of Systemic Autoimmunity Caused by Mutations of FOXP3, a Critical Regulator of T-Cell Homeostasis. Curr. Opin. Rheumatol. 15 (4), 430-435. doi:10.1097/00002281-200307000-00010

Gandhi, R., Kumar, D., Burns, E. J., Nadeau, M., Dake, B., Laroni, A., et al. (2010). Activation of the Aryl Hydrocarbon Receptor Induces Human Type 1 Regulatory T Cell-like and Foxp3(+) Regulatory T Cells. Nat. Immunol. 11 (9), 846-853. doi:10.1038/ni.1915

Gao, S., Hao, B., Yang, X. F., and Chen, W. Q. (2014). Decreased CD200R Expression on Monocyte-Derived Macrophages Correlates with Th17/Treg Imbalance and Disease Activity in Rheumatoid Arthritis Patients. Inflamm. Res. 63 (6), 441-450.

Garin, M. I., Chu, C. C., Golshayan, D., Cernuda-Morollon, E., Wait, R., and Lechler, R. I. (2007). Galectin-1: a Key Effector of Regulation Mediated by CD4+CD25+ T Cells. Blood 109 (5), 2058-2065. doi:10.1182/blood-2006-04016451

Ghiringhelli, F., Puig, P. E., Roux, S., Parcellier, A., Schmitt, E., Solary, E., et al. (2005). Tumor Cells Convert Immature Myeloid Dendritic Cells into TGF-Beta-Secreting Cells Inducing CD4+CD25+ Regulatory T Cell Proliferation. J. Exp. Med. 202 (7), 919-929. doi:10.1084/jem.20050463

Ghoryani, M., Shariati-Sarabi, Z., Tavakkol-Afshari, J., Ghasemi, A., Poursamimi, J., and Mohammadi, M. (2019). Amelioration of Clinical Symptoms of Patients with Refractory Rheumatoid Arthritis Following Treatment with Autologous Bone Marrow-Derived Mesenchymal Stem Cells: A Successful Clinical Trial in Iran. Biomed. Pharmacother. 109, 1834-1840. doi:10.1016/j.biopha.2018.11.056

Giganti, G., Atif, M., Mohseni, Y., Mastronicola, D., Grageda, N., Povoleri, G. A., et al. (2021). Treg Cell Therapy: How Cell Heterogeneity Can Make the Difference. Eur. J. Immunol. 51 (1), 39-55. doi:10.1002/eji.201948131

Go, E., Yoo, S. J., Choi, S., Sun, P., Jung, M. K., Kwon, S., et al. (2021). Peripheral Blood from Rheumatoid Arthritis Patients Shows Decreased Treg CD25 Expression and Reduced Frequency of Effector Treg Subpopulation. Cells 10 (4). doi:10.3390/cells10040801

Gondek, D. C., Lu, L. F., Quezada, S. A., Sakaguchi, S., and Noelle, R. J. (2005). Cutting Edge: Contact-Mediated Suppression by CD4+CD25+ Regulatory Cells
Involves a Granzyme B-dependent, Perforin-independent Mechanism. J. Immunol. 174 (4), 1783-1786. doi:10.4049/jimmunol.174.4.1783

Grossman, W. J., Verbsky, J. W., Barchet, W., Colonna, M., Atkinson, J. P., and Ley, T. J. (2004). Human T Regulatory Cells Can Use the Perforin Pathway to Cause Autologous Target Cell Death. Immunity 21 (4), 589-601. doi:10.1016/ j.immuni.2004.09.002

Gupta, V., Katiyar, S., Singh, A., Misra, R., and Aggarwal, A. (2018). CD39 Positive Regulatory $\mathrm{T}$ Cell Frequency as a Biomarker of Treatment Response to Methotrexate in Rheumatoid Arthritis. Int. J. Rheum. Dis. 21 (8), 1548-1556. doi:10.1111/1756-185X.13333

Han, X., Su, D., Xian, X., Zhou, M., Li, X., Huang, J., et al. (2016). Inhibitory effects of Saussurea involucrata (Kar. et Kir.) Sch. -Bip. on adjuvant arthritis in rats. J. Ethnopharmacol. 194, 228-235. doi:10.1016/j.jep.2016.09.008

Hashemi, V., Farrokhi, A. S., Tanomand, A., Babaloo, Z., Hojjat-Farsangi, M., Anvari, E., et al. (2018). Polymorphism of Foxp3 Gene Affects the Frequency of Regulatory $\mathrm{T}$ Cells and Disease Activity in Patients with Rheumatoid Arthritis in Iranian Population. Immunol. Lett. 204, 16-22. doi:10.1016/j.imlet.2018.10.001

Hayatsu, N., Miyao, T., Tachibana, M., Murakami, R., Kimura, A., Kato, T., et al. (2017). Analyses of a Mutant Foxp3 Allele Reveal BATF as a Critical Transcription Factor in the Differentiation and Accumulation of Tissue Regulatory $\mathrm{T}$ Cells. Immunity 47 (2), 268-283. doi:10.1016/ j.immuni.2017.07.008

Horak, I., Lohler, J., Ma, A., and Smith, K. A. (1995). Interleukin-2 Deficient Mice: a New Model to Study Autoimmunity and Self-Tolerance. Immunol. Rev. 148, 35-44. doi:10.1111/j.1600-065x.1995.tb00092.x

Huang, Y., Wang, H., Ba, X., Chen, Z., Wang, Y., Qin, K., et al. (2020). Decipher Manifestations and Treg/Th17 Imbalance in Multi-Staging Rheumatoid Arthritis and Correlation with TSDR/RORC Methylation. Mol. Immunol. 127, 1-11. doi:10.1016/j.molimm.2020.08.002

Iwaszkiewicz-Grzes, D., Piotrowska, M., Gliwinski, M., Urban- Wójciuk, Z., and Trzonkowski, P. (2021). Antigenic Challenge Influences Epigenetic Changes in Antigen-specific T Regulatory Cells. Front. Immunol. 12, 642678. doi:10.3389/ fimmu.2021.642678

Ji, H. B., Liao, G., Faubion, W. A., Abadia-Molina, A. C., Cozzo, C., Laroux, F. S., et al. (2004). Cutting Edge: the Natural Ligand for Glucocorticoid-Induced TNF Receptor-Related Protein Abrogates Regulatory $\mathrm{T}$ Cell Suppression. J. Immunol. 172 (10), 5823-5827. doi:10.4049/jimmunol.172.10.5823

Ji, L., Geng, Y., Zhou, W., and Zhang, Z. (2016). A Study on Relationship Among Apoptosis Rates, Number of Peripheral T Cell Subtypes and Disease Activity in Rheumatoid Arthritis. Int. J. Rheum. Dis. 19 (2), 167-171.

Jiang, Q., Yang, G., Liu, Q., Wang, S., and Cui, D. (2021). Function and Role of Regulatory T Cells in Rheumatoid Arthritis. Front. Immunol. 12, 626193. doi:10.3389/fimmu.2021.626193

Jin, S., Sun, S., Ling, H., Ma, J., Zhang, X., Xie, Z., et al. (2021). Protectin DX Restores Treg/T(h)17 Cell Balance in Rheumatoid Arthritis by Inhibiting NLRP3 Inflammasome via miR-20a. Cell Death Dis. 12 (3), 280. doi:10.1038/s41419-021-03562-6

Kailashiya, V., Singh, U., Rana, R., Singh, N. K., Dash, D., and Kailashiya, J. (2019). Regulatory T Cells and Their Association with Serum Markers and Symptoms in Systemic Lupus Erythematosus and Rheumatoid Arthritis. Immunol. Invest. 48 (1), 64-78. doi:10.1080/08820139.2018.1527852

Kanjana, K., Chevaisrakul, P., Matangkasombut, P., Paisooksantivatana, K., and Lumjiaktase, P. (2020). Inhibitory Activity of FOXP3+ Regulatory T Cells Reveals High Specificity for Displaying Immune Tolerance in Remission State Rheumatoid Arthritis. Sci. Rep. 10 (1), 19789. doi:10.1038/s41598-020-76168-1

Khattab, S. S., El-Saied, A. M., Mohammed, R. A., and Mohamed, E. E. (2016). CD4+ CD25+ CD127low Regulatory T Cells as Indicator of Rheumatoid Arthritis Disease Activity. Egypt. J. Immunol. 23 (2), 87-95.

Khattri, R., Cox, T., Yasayko, S. A., and Ramsdell, F. (2003). An Essential Role for Scurfin in CD4+CD25+ T Regulatory Cells. Nat. Immunol. 4 (4), 337-342. doi:10.1038/ni909

Khoshmirsafa, M., Seif, F., Bagheri, N., Beshkar, P., Mousavi, M., and Shirzad, H. (2018). Correlation of Interleukin 6 and Transforming Growth Factor $\beta 1$ with Peripheral Blood Regulatory T Cells in Rheumatoid Arthritis Patients: a Potential Biomarker. Cent. Eur. J. Immunol. 43 (3), 281-288. doi:10.5114/ ceji.2018.80047

Kim, J. R., Chae, J. N., Kim, S. H., and Ha, J. S. (2012). Subpopulations of Regulatory T Cells in Rheumatoid Arthritis, Systemic Lupus Erythematosus, 
and Behcet's Disease. J. Korean Med. Sci. 27 (9), 1009-1013. doi:10.3346/ jkms.2012.27.9.1009

Kim, W. H., Lillehoj, H. S., and Min, W. (2019). Indole Treatment Alleviates Intestinal Tissue Damage Induced by Chicken Coccidiosis through Activation of the Aryl Hydrocarbon Receptor. Front. Immunol. 10, 560. doi:10.3389/ fimmu.2019.00560

Klatzmann, D., and Abbas, A. K. (2015). The Promise of Low-Dose Interleukin-2 Therapy for Autoimmune and Inflammatory Diseases. Nat. Rev. Immunol. 15 (5), 283-294. doi:10.1038/nri3823

Kosmaczewska, A., Ciszak, L., Swierkot, J., Szteblich, A., Kosciow, K., and Frydecka, I. (2015). Exogenous IL-2 Controls the Balance in Th1, Th17, and Treg Cell Distribution in Patients with Progressive Rheumatoid Arthritis Treated with TNF-Alpha Inhibitors. Inflammation 38 (2), 765-774. doi:10.1007/s10753-0149987-x

Kragsnaes, M. S., Kjeldsen, J., Horn, H. C., Munk, H. L., Pedersen, F. M., Holt, H. M., et al. (2018). Efficacy and Safety of Faecal Microbiota Transplantation in Patients with Psoriatic Arthritis: Protocol for a 6-month, Double-Blind, Randomised, Placebo-Controlled Trial. BMJ Open 8 (4), e019231. doi:10.1136/bmjopen-2017-019231

Kravchenko, P. N., Zhulai, G. A., Churov, A. V., Oleinik, E. K., Oleinik, V. M., Barysheva, O. Y., et al. (2016). [Subpopulations of Regulatory T-Lymphocytes in the Peripheral Blood of Patients with Rheumatoid Arthritis]. Vestn Ross Akad Med. Nauk (2), 148-153. doi:10.15690/vramn656

Kullberg, M. C., Hay, V., Cheever, A. W., Mamura, M., Sher, A., Letterio, J. J., et al. (2005). TGF-beta1 Production by CD4+ CD25+ Regulatory T Cells Is Not Essential for Suppression of Intestinal Inflammation. Eur. J. Immunol. 35 (10), 2886-2895. doi:10.1002/eji.200526106

Kumar, S., Wang, J., Thomson, A. W., and Gandhi, C. R. (2017). Hepatic Stellate Cells Increase the Immunosuppressive Function of Natural Foxp3+ Regulatory T Cells via Ido-induced AhR Activation. J. Leukoc. Biol. 101 (2), 429-438. doi:10.1189/jlb.2A0516-239R

Li, M., Ma, K., Feng, Z., Wang, J., Zhou, X., and Zhou, L. (2020b). Differential Long Non-coding RNA Expression Profiles in the Peripheral Blood and CD4(+) T Cells of Patients with Active Rheumatoid Arthritis. Exp. Ther. Med. 20 (1), 461-471. doi:10.3892/etm.2020.8681

Li, M. O., Wan, Y. Y., and Flavell, R. A. (2007). T Cell-Produced Transforming Growth Factor-Betal Controls T Cell Tolerance and Regulates Th1- and Th17Cell Differentiation. Immunity 26 (5), 579-591. doi:10.1016/ j.immuni.2007.03.014

Li, N., Ma, T., Han, J., Wang, J., Zhang, J., and Zheng, S. (2014). Increased Apoptosis Induction in CD4+ CD25+ Foxp3+ T Cells Contributes to Enhanced Disease Activity in Patients with Rheumatoid Arthritis through IL-10 Regulation. Eur. Rev. Med. Pharmaco. 18 (1), 78-85.

Li, S., Wan, J., Anderson, W., Sun, H., Zhang, H., Peng, X., et al. (2016a). Downregulation of IL-10 Secretion by Treg Cells in Osteoarthritis Is Associated with a Reduction in Tim-3 Expression. Biomed. Pharmacother. 79, 159-165. doi:10.1016/j.biopha.2016.01.036

Li, S., Wu, Z., Li, L., and Liu, X. (2016b). Interleukin-6 (IL-6) Receptor Antagonist Protects against Rheumatoid Arthritis. Med. Sci. Monit. 22, 2113-2118. doi: $10.12659 / \mathrm{msm} .896355$

Li, X., Lu, C., Fan, D., Lu, X., Xia, Y., Zhao, H., et al. (2020a). Human Umbilical Mesenchymal Stem Cells Display Therapeutic Potential in Rheumatoid Arthritis by Regulating Interactions between Immunity and Gut Microbiota via the Aryl Hydrocarbon Receptor. Front. Cel. Dev. Biol. 8, 131. doi:10.3389/ fcell.2020.00131

Liang, B., Workman, C., Lee, J., Chew, C., Dale, B. M., Colonna, L., et al. (2008). Regulatory T Cells Inhibit Dendritic Cells by Lymphocyte Activation Gene-3 Engagement of MHC Class II. J. Immunol. 180 (9), 5916-5926. doi:10.4049/ jimmunol.180.9.5916

Lin, H., Zhang, G. D., Tang, H. H., Wang, Y., Liu, Y., and Zhao, Y. (2014). [The Change of CD4+ CD25+ Regulatory T Cells in Patients with Rheumatoid Arthritis]. Sichuan Da Xue Xue Bao Yi Xue Ban 45 (4), 618-622.

Liu, C., Wang, D., Lu, S., Xu, Q., Zhao, L., Zhao, J., et al. (2018). Increased Circulating Follicular Treg Cells Are Associated with Lower Levels of Autoantibodies in Patients with Rheumatoid Arthritis in Stable Remission. Arthritis Rheumatol. 70 (5), 711-721. doi:10.1002/art.40430

Liu, X., Zhang, J., Zou, Q., Zhong, B., Wang, H., Mou, F., et al. (2016). Lactobacillus Salivarius Isolated from Patients with Rheumatoid Arthritis Suppresses
Collagen-Induced Arthritis and Increases Treg Frequency in Mice. J. Interferon Cytokine Res. 36 (12), 706-712. doi:10.1089/jir.2016.0057

Lo, J., Chan, L., and Flynn, S. (2021). A Systematic Review of the Incidence, Prevalence, Costs, and Activity and Work Limitations of Amputation, Osteoarthritis, Rheumatoid Arthritis, Back Pain, Multiple Sclerosis, Spinal Cord Injury, Stroke, and Traumatic Brain Injury in the United States: A 2019 Update. Arch. Phys. Med. Rehabil. 102 (1), 115-131. doi:10.1016/ j.apmr.2020.04.001

Luo, D., Zuo, Z., Zhao, H., Tan, Y., and Xiao, C. (2019). Immunoregulatory Effects of Tripterygium Wilfordii Hook F and its Extracts in Clinical Practice. Front. Med. 13 (5), 556-563. doi:10.1007/s11684-018-0649-5

Lv, Q., Wang, K., Qiao, S., Yang, L., Xin, Y., Dai, Y., et al. (2018). Norisoboldine, a Natural AhR Agonist, Promotes Treg Differentiation and Attenuates Colitis via Targeting Glycolysis and Subsequent NAD(+)/SIRT1/SUV39H1/H3K9me3 Signaling Pathway. Cel Death Dis. 9 (3), 258. doi:10.1038/s41419-018-0297-3

Lynch, S. V., and Pedersen, O. (2016). The Human Intestinal Microbiome in Health and Disease. N. Engl. J. Med. 375 (24), 2369-2379. doi:10.1056/NEJMra1600266

Ma, A., Yang, Y., Wang, Q., Wang, Y., Wen, J., and Zhang, Y. (2017). Antiinflammatory Effects of Oxymatrine on Rheumatoid Arthritis in Rats via Regulating the Imbalance between Treg and Th17 Cells. Mol. Med. Rep. 15 (6), 3615-3622. doi:10.3892/mmr.2017.6484

Ma, D., Xu, K., Zhang, G., Liu, Y., Gao, J., Tian, M., et al. (2019). Immunomodulatory Effect of Human Umbilical Cord Mesenchymal Stem Cells on $\mathrm{T}$ Lymphocytes in Rheumatoid Arthritis. Int. Immunopharmacol. 74, 105687. doi:10.1016/j.intimp.2019.105687

Mahmud, S. A., Manlove, L. S., Schmitz, H. M., Xing, Y., Wang, Y., Owen, D. L., et al. (2014). Costimulation via the Tumor-Necrosis Factor Receptor Superfamily Couples TCR Signal Strength to the Thymic Differentiation of Regulatory T Cells. Nat. Immunol. 15 (5), 473-481. doi:10.1038/ni.2849

Malek, T. R., Yu, A., Vincek, V., Scibelli, P., and Kong, L. (2002). CD4 Regulatory T Cells Prevent Lethal Autoimmunity in IL-2Rbeta-deficient Mice. Implications for the Nonredundant Function of IL-2. Immunity 17 (2), 167-178. doi:10.1016/s1074-7613(02)00367-9

Matsuki, F., Saegusa, J., Miyamoto, Y., Misaki, K., Kumagai, S., and Morinobu, A. (2013). CD45RA-Foxp3(high) Activated/effector Regulatory $\mathrm{T}$ Cells in the CCR7 + CD45RA-CD27 + CD28+central Memory Subset Are Decreased in Peripheral Blood from Patients with Rheumatoid Arthritis. Biochem. Biophys. Res. Commun. 438 (4), 778-783. doi:10.1016/j.bbrc.2013.05.120

Mcgovern, J. L., Nguyen, D. X., Notley, C. A., Mauri, C., Isenberg, D. A., and Ehrenstein, M. R. (2012). Th17 Cells Are Restrained by Treg Cells via the Inhibition of Interleukin-6 in Patients with Rheumatoid Arthritis Responding to Anti-tumor Necrosis Factor Antibody Therapy. Arthritis Rheum. 64 (10), 3129-3138. doi:10.1002/art.34565

Mchugh, R. S., Whitters, M. J., Piccirillo, C. A., Young, D. A., Shevach, E. M., Collins, M., et al. (2002). CD4(+)CD25(+) Immunoregulatory T Cells: Gene Expression Analysis Reveals a Functional Role for the Glucocorticoid-Induced TNF Receptor. Immunity 16 (2), 311-323. doi:10.1016/s1074-7613(02)00280-7

Milward, K. F., Wood, K. J., and Hester, J. (2017). Enhancing Human Regulatory T Cells In Vitro for Cell Therapy Applications. Immunol. Lett. 190, 139-147. doi:10.1016/j.imlet.2017.08.012

Moore, C., Sauma, D., Reyes, P. A., Morales, J., Rosemblatt, M., Bono, M. R., et al. (2010). Dendritic Cells and B Cells Cooperate in the Generation of CD4(+) CD25(+)FOXP3(+) Allogeneic T Cells. Transpl 42 (1), 371-375. doi:10.1016/ j.transproceed.2009.12.044

Morgan, M. E., Flierman, R., van Duivenvoorde, L. M., Witteveen, H. J., van Ewijk, W., van Laar, J. M., et al. (2005). Effective Treatment of Collagen-Induced Arthritis by Adoptive Transfer of CD25+ Regulatory T Cells. Arthritis Rheum. 52 (7), 2212-2221. doi:10.1002/art.21195

Nakachi, S., Sumitomo, S., Tsuchida, Y., Tsuchiya, H., Kono, M., Kato, R., et al. (2017). Interleukin-10-producing LAG3(+) Regulatory T Cells Are Associated with Disease Activity and Abatacept Treatment in Rheumatoid Arthritis. Arthritis Res. Ther. 19 (1), 97. doi:10.1186/s13075-017-1309-x

Nakayamada, S., Kubo, S., Yoshikawa, M., Miyazaki, Y., Yunoue, N., Iwata, S., et al. (2017). Differential Effects of Biological DMARDs on Peripheral Immune Cell Phenotypes in Patients with Rheumatoid Arthritis. Rheumatology.

Nie, H., Zheng, Y., Li, R., Guo, T. B., He, D., Fang, L., et al. (2013). Phosphorylation of FOXP3 Controls Regulatory T Cell Function and Is Inhibited by TNF-Alpha in Rheumatoid Arthritis. Nat. Med. 19 (3), 322-328. doi:10.1038/nm.3085 
Niu, H. Q., Li, Z. H., Zhao, W. P., Zhao, X. C., Zhang, C., Luo, J., et al. (2020). Sirolimus Selectively Increases Circulating Treg Cell Numbers and Restores the Th17/Treg Balance in Rheumatoid Arthritis Patients with Low Disease Activity or in DAS28 Remission Who Previously Received Conventional DiseaseModifying Anti-rheumatic Drugs. Clin. Exp. Rheumatol. 38 (1), 58-66.

Niu, Q., Cai, B., Huang, Z. C., Shi, Y. Y., and Wang, L. L. (2012). Disturbed Th17/ Treg Balance in Patients with Rheumatoid Arthritis. Rheumatol. Int. 32 (9), 2731-2736. doi:10.1007/s00296-011-1984-x

Niu, Q., Huang, Z. C., Wu, X. J., Jin, Y. X., An, Y. F., Li, Y. M., et al. (2018). Enhanced IL-6/phosphorylated STAT3 Signaling Is Related to the Imbalance of Circulating T Follicular Helper/T Follicular Regulatory Cells in Patients with Rheumatoid Arthritis. Arthritis Res. Ther. 20 (1), 200. doi:10.1186/s13075-018-1690-0

Oberle, N., Eberhardt, N., Falk, C. S., Krammer, P. H., and Suri-Payer, E. (2007). Rapid Suppression of Cytokine Transcription in Human CD4+CD25 T Cells by CD4+Foxp3+ Regulatory T Cells: independence of IL-2 Consumption, TGFBeta, and Various Inhibitors of TCR Signaling. J. Immunol. 179 (6), 3578-3587. doi:10.4049/jimmunol.179.6.3578

Oettel, A., Lorenz, M., Stangl, V., Costa, S. D., Zenclussen, A. C., and Schumacher, A. (2016). Human Umbilical Vein Endothelial Cells foster Conversion of CD4+CD25-Foxp3- T Cells into CD4+Foxp3+ Regulatory T Cells via Transforming Growth Factor-Beta. Sci. Rep. 6, 23278. doi:10.1038/srep23278

Oh, J. S., Kim, Y. G., Lee, S. G., So, M. W., Choi, S. W., Lee, C. K., et al. (2013). The Effect of Various Disease-Modifying Anti-rheumatic Drugs on the Suppressive Function of CD4(+)CD25(+) Regulatory T Cells. Rheumatol. Int. 33 (2), 381-388. doi:10.1007/s00296-012-2365-9

Ohta, A., and Sitkovsky, M. (2014). Extracellular Adenosine-Mediated Modulation of Regulatory T Cells. Front. Immunol. 5, 304. doi:10.3389/fimmu.2014.00304

Pandiyan, P., Zheng, L., Ishihara, S., Reed, J., and Lenardo, M. J. (2007). CD4+CD25+Foxp3+ Regulatory $\mathrm{T}$ Cells Induce Cytokine DeprivationMediated Apoptosis of Effector CD4+ T Cells. Nat. Immunol. 8 (12), 1353-1362. doi:10.1038/ni1536

Paradowska-Gorycka, A., Wajda, A., Romanowska-Prchnicka, K., Walczuk, E., Kuca-Warnawin, E., Kmiolek, T., et al. (2020). Th17/Treg-Related Transcriptional Factor Expression and Cytokine Profile in Patients with Rheumatoid Arthritis. Front. Immunol. 11, 572858. doi:10.3389/ fimmu.2020.572858

Pawlowska, J., Smolenska, Z., Daca, A., Witkowski, J. M., and Bryl, E. (2011). Older Age of Rheumatoid Arthritis Onset Is Associated with Higher Activation Status of Peripheral Blood CD4(+) T Cells and Disease Activity. Clin. Exp. Immunol. 163 (2), 157-164. doi:10.1111/j.1365-2249.2010.04294.x

Pelleitier, M., and Montplaisir, S. (1975). The Nude Mouse: a Model of Deficient T-Cell Function. Methods Achiev Exp. Pathol. 7, 149-166.

Peng, J., Lu, X., Xie, K., Xu, Y., He, R., Guo, L., et al. (2019). Dynamic Alterations in the Gut Microbiota of Collagen-Induced Arthritis Rats Following the Prolonged Administration of Total Glucosides of Paeony. Front. Cel. Infect. Microbiol. 9, 204. doi:10.3389/fcimb.2019.00204

Pesce, B., Soto, L., Sabugo, F., Wurmann, P., Cuchacovich, M., Lopez, M. N., et al. (2013). Effect of Interleukin-6 Receptor Blockade on the Balance between Regulatory T Cells and T Helper Type 17 Cells in Rheumatoid Arthritis Patients. Clin. Exp. Immunol. 171 (3), 237-242. doi:10.1111/cei.12017

Petrillo, M. G., Ronchetti, S., Ricci, E., Alunno, A., Gerli, R., Nocentini, G., et al. (2015). GITR+ Regulatory T Cells in the Treatment of Autoimmune Diseases. Autoimmun. Rev. 14 (2), 117-126. doi:10.1016/j.autrev.2014.10.011

Piccirillo, C. A., Letterio, J. J., Thornton, A. M., Mchugh, R. S., Mamura, M., Mizuhara, H., et al. (2002). CD4(+)CD25(+) Regulatory T Cells Can Mediate Suppressor Function in the Absence of Transforming Growth Factor Betal Production and Responsiveness. J. Exp. Med. 196 (2), 237-246. doi:10.1084/ jem. 20020590

Ptacek, J., Hawtin, R. E., Sun, D., Louie, B., Evensen, E., Mittleman, B. B., et al. (2021). Diminished Cytokine-Induced Jak/STAT Signaling Is Associated with Rheumatoid Arthritis and Disease Activity. PLoS One 16 (1), e0244187. doi:10.1371/journal.pone.0244187

Qian, C., Kuang, M., and Wang, Y. (2017). Effect of Qianghuo Erhuang Decoction on T Regulatory and T Helper 17 Cells in Treatment of Adjuvant-Induced Arthritis in Rats. Sci. Rep. 7 (1), 17198. doi:10.1038/s41598-017-17566-w

Quintana, F. J., Basso, A. S., Iglesias, A. H., Korn, T., Farez, M. F., Bettelli, E., et al. (2008). Control of $\mathrm{T}(\mathrm{reg})$ and $\mathrm{T}(\mathrm{H}) 17$ Cell Differentiation by the Aryl Hydrocarbon Receptor. Nature 453 (7191), 65-71. doi:10.1038/nature06880
Quintana, F. J. (2013). The Aryl Hydrocarbon Receptor: a Molecular Pathway for the Environmental Control of the Immune Response. Immunology 138 (3), 183-189. doi:10.1111/imm.12046

Qureshi, O. S., Zheng, Y., Nakamura, K., Attridge, K., Manzotti, C., Schmidt, E. M., et al. (2011). Trans-endocytosis of CD80 and CD86: a Molecular Basis for the Cell-Extrinsic Function of CTLA-4. Science 332 (6029), 600-603. doi:10.1126/ science. 1202947

Rapetti, L., Chavele, K. M., Evans, C. M., and Ehrenstein, M. R. (2015). B Cell Resistance to Fas-Mediated Apoptosis Contributes to Their Ineffective Control by Regulatory T Cells in Rheumatoid Arthritis. Ann. Rheum. Dis. 74 (1), 294-302. doi:10.1136/annrheumdis-2013-204049

Read, S., Malmstrom, V., and Powrie, F. (2000). Cytotoxic T LymphocyteAssociated Antigen 4 Plays an Essential Role in the Function of CD25(+) CD4(+) Regulatory Cells that Control Intestinal Inflammation. J. Exp. Med. 192 (2), 295-302. doi:10.1084/jem.192.2.295

Roager, H. M., and Licht, T. R. (2018). Microbial Tryptophan Catabolites in Health and Disease. Nat. Commun. 9 (1), 3294. doi:10.1038/s41467-018-05470-4

Robbins, K., Bissonnette, R., Maeda-Chubachi, T., Ye, L., Peppers, J., Gallagher, K., et al. (2019). Phase 2, Randomized Dose-Finding Study of Tapinarof (GSK2894512 Cream) for the Treatment of Plaque Psoriasis. J. Am. Acad. Dermatol. 80 (3), 714-721. doi:10.1016/j.jaad.2018.10.037

Ronchetti, S., Ricci, E., Petrillo, M. G., Cari, L., Migliorati, G., Nocentini, G., et al. (2015). Glucocorticoid-induced Tumour Necrosis Factor Receptor-Related Protein: a Key Marker of Functional Regulatory T Cells. J. Immunol. Res. 2015, 171520. doi:10.1155/2015/171520

Round, J. L., Lee, S. M., Li, J., Tran, G., Jabri, B., Chatila, T. A., et al. (2011). The Toll-like Receptor 2 Pathway Establishes Colonization by a Commensal of the Human Microbiota. Science 332 (6032), 974-977. doi:10.1126/science.1206095

Sakaguchi, S., Sakaguchi, N., Asano, M., Itoh, M., and Toda, M. (1995). Immunologic Self-Tolerance Maintained by Activated T Cells Expressing IL-2 Receptor AlphaChains (CD25). Breakdown of a Single Mechanism of Self-Tolerance Causes Various Autoimmune Diseases. J. Immunol. 155 (3), 1151-1164.

Salomon, B. L. (2021). Insights into the Biology and Therapeutic Implications of TNF and Regulatory T Cells. Nat. Rev. Rheumatol. doi:10.1038/s41584-02100639-6

Samson, M., Audia, S., Janikashvili, N., Ciudad, M., Trad, M., Fraszczak, J., et al. (2012). Brief Report: Inhibition of Interleukin-6 Function Corrects Th17/Treg Cell Imbalance in Patients with Rheumatoid Arthritis. Arthritis Rheum. 64 (8), 2499-2503. doi:10.1002/art.34477

Sato, K., Takahashi, N., Kato, T., Matsuda, Y., Yokoji, M., Yamada, M., et al. (2017). Aggravation of Collagen-Induced Arthritis by Orally Administered Porphyromonas Gingivalis through Modulation of the Gut Microbiota and Gut Immune System. Sci. Rep. 7 (1), 6955. doi:10.1038/s41598-017-07196-7

Seddon, B., and Mason, D. (1999). Regulatory T Cells in the Control of Autoimmunity: the Essential Role of Transforming Growth Factor Beta and Interleukin 4 in the Prevention of Autoimmune Thyroiditis in Rats by Peripheral CD4(+)CD45RC- Cells and CD4(+)CD8(-) Thymocytes. J. Exp. Med. 189 (2), 279-288. doi:10.1084/jem.189.2.279

Setoguchi, R., Hori, S., Takahashi, T., and Sakaguchi, S. (2005). Homeostatic Maintenance of naturalFoxp3+CD25+CD4+ Regulatory T Cells by Interleukin (IL)-2 and Induction of Autoimmune Disease by IL-2 Neutralization. J. Exp. Med. 201 (5), 723-735. doi:10.1084/jem.20041982

Sewgobind, V. D., Quaedackers, M. E., van der Laan, L. J., Kraaijeveld, R., Korevaar, S. S., Chan, G., et al. (2010). The Jak Inhibitor CP-690,550 Preserves the Function of CD4CD25FoxP3 Regulatory T Cells and Inhibits Effector T Cells. Am. J. Transpl. 10 (8), 1785-1795. doi:10.1111/j.1600-6143.2010.03200.x

Shevyrev, D., Tereshchenko, V., Kozlov, V., Sizikov, A., Chumasova, O., and Koksharova, V. (2021). T-regulatory Cells from Patients with Rheumatoid Arthritis Retain Suppressor Functions In Vitro. Exp. Ther. Med. 21 (3), 209. doi:10.3892/etm.2021.9641

Shimizu, J., Yamazaki, S., Takahashi, T., Ishida, Y., and Sakaguchi, S. (2002). Stimulation of CD25(+)CD4(+) Regulatory T Cells through GITR Breaks Immunological Self-Tolerance. Nat. Immunol. 3 (2), 135-142. doi:10.1038/ ni759

Singh, N., Gurav, A., Sivaprakasam, S., Brady, E., Padia, R., Shi, H., et al. (2014). Activation of Gpr109a, Receptor for Niacin and the Commensal Metabolite Butyrate, Suppresses Colonic Inflammation and Carcinogenesis. Immunity 40 (1), 128-139. doi:10.1016/j.immuni.2013.12.007 
Smith, P. M., Howitt, M. R., Panikov, N., Michaud, M., Gallini, C. A., Bohlooly-Y, M., et al. (2013). The Microbial Metabolites, Short-Chain Fatty Acids, Regulate Colonic Treg Cell Homeostasis. Science 341 (6145), 569-573. doi:10.1126/science.1241165

Snow, J. W., Abraham, N., Ma, M. C., Herndier, B. G., Pastuszak, A. M., and Goldsmith, M. A. (2003). Loss of Tolerance and Autoimmunity Affecting Multiple Organs in STAT5A/5B-Deficient Mice. J. Immunol. 171(10), 5042-5050. doi:10.4049/jimmunol.171.10.5042

Song, M., and Ma, X. (2016). The Immunobiology of Interleukin-35 and its Regulation and Gene Expression. Adv. Exp. Med. Biol. 941, 213-225. doi:10.1007/978-94-024-0921-5_10

Su, D., Shen, M., Gu, B., Wang, X., Wang, D., Li, X., et al. (2016). (99Tc-methylene Diphosphonate Improves Rheumatoid Arthritis Disease Activity by Increasing the Frequency of Peripheral Gammadelta T Cells and CD4(+) CD25(+) Foxp3(+) Tregs. Int. J. Rheum. Dis. 19 (6), 586-593. doi:10.1111/1756185X.12292

Su, Q., Jing, J., Li, W., Ma, J., Zhang, X., Wang, Z., et al. (2019). Impaired Tip60Mediated Foxp3 Acetylation Attenuates Regulatory T Cell Development in Rheumatoid Arthritis. J. Autoimmun. 100, 27-39. doi:10.1016/ j.jaut.2019.02.007

Sun, H., Gao, W., Pan, W., Zhang, Q., Wang, G., Feng, D., et al. (2017). Tim3(+) Foxp3 (+) Treg Cells Are Potent Inhibitors of Effector T Cells and Are Suppressed in Rheumatoid Arthritis. Inflammation 40 (4), 1342-1350. doi:10.1007/s10753-017-0577-6

Surbek, M., Tse, W., Moriggl, R., and Han, X. (2021). A Centric View of JAK/ STAT5 in Intestinal Homeostasis, Infection, and Inflammation. Cytokine 139, 155392. doi:10.1016/j.cyto.2020.155392

Tag, H. M., Khaled, H. E., Ismail, H. A., and El-Shenawy, N. S. (2016). Evaluation of Anti-inflammatory Potential of the Ethanolic Extract of the Saussurea Lappa Root (costus) on Adjuvant-Induced Monoarthritis in Rats. J. Basic Clin. Physiol. Pharmacol. 27 (1), 71-78. doi:10.1515/jbcpp-2015-0044

Tai, X., Van Laethem, F., Pobezinsky, L., Guinter, T., Sharrow, S. O., Adams, A., et al. (2012). Basis of CTLA-4 Function in Regulatory and Conventional CD4(+) T Cells. Blood 119 (22), 5155-5163. doi:10.1182/blood-2011-11388918

Tang, T. T., Song, Y., Ding, Y. J., Liao, Y. H., Yu, X., Du, R., et al. (2011). Atorvastatin Upregulates Regulatory $\mathrm{T}$ Cells and Reduces Clinical Disease Activity in Patients with Rheumatoid Arthritis. J. Lipid Res. 52 (5), 1023-1032. doi:10.1194/jlr.M010876

Telesford, K. M., Yan, W., Ochoa-Reparaz, J., Pant, A., Kircher, C., Christy, M. A., et al. (2015). A Commensal Symbiotic Factor Derived from Bacteroides Fragilis Promotes Human CD39(+)Foxp3(+) T Cells and Treg Function. Gut Microbes 6 (4), 234-242. doi:10.1080/19490976.2015.1056973

Thornton, A. M., Donovan, E. E., Piccirillo, C. A., and Shevach, E. M. (2004). Cutting Edge: IL-2 Is Critically Required for the In Vitro Activation of CD4+CD25+ T Cell Suppressor Function. J. Immunol. 172 (11), 6519-6523. doi:10.4049/jimmunol.172.11.6519

van der Geest Ks, K. S., Ja, P., Wh, A., Hw, K., Bj, K., van den Berg, A., et al. (2015). SF Treg Cells Transcribing High Levels of Bcl-2 and microRNA-21 Demonstrate Limited Apoptosis in RA. Rheumatology (Oxford, England) 54 (5), 950-958. doi:10.1093/rheumatology/keu407

van Roon, J. A., Hartgring, S. A., van der Wurff-Jacobs, K. M., Bijlsma, J. W., and Lafeber, F. P. (2010). Numbers of CD25+Foxp3+ T Cells that Lack the IL-7 Receptor Are Increased Intra-articularly and Have Impaired Suppressive Function in RA Patients. Rheumatology (Oxford) 49 (11), 2084-2089. doi:10.1093/rheumatology/keq237

Vercoulen, Y., Wehrens, E. J., van Teijlingen, N. H., de Jager, W., Beekman, J. M., and Prakken, B. J. (2009). Human Regulatory T Cell Suppressive Function Is Independent of Apoptosis Induction in Activated Effector T Cells. PLoS One 4 (9), e7183. doi:10.1371/journal.pone.0007183

Vitales-Noyola, M., Layseca-Espinosa, E., Baranda, L., Abud-Mendoza, C., NiñoMoreno, P., Monsiváis-Urenda, A., et al. (2018). Analysis of Sodium Chloride Intake and Treg/Th17 Lymphocytes in Healthy Individuals and Patients with Rheumatoid Arthritis or Systemic Lupus Erythematosus. J. Immunol. Res. 2018, 9627806. doi:10.1155/2018/9627806

Walter, G. J., Evans, H. G., Menon, B., Gullick, N. J., Kirkham, B. W., Cope, A. P., et al. (2013). Interaction with Activated Monocytes Enhances Cytokine Expression and Suppressive Activity of Human CD4+CD45ro+CD25+CD127(low) Regulatory T Cells. Arthritis Rheum. 65 (3), 627-638. doi:10.1002/art.37832
Walter, G. J., Fleskens, V., Frederiksen, K. S., Rajasekhar, M., Menon, B., Gerwien, J. G., et al. (2016). Phenotypic, Functional, and Gene Expression Profiling of Peripheral CD45RA+ and CD45RO+ CD4+CD25+CD127(low) Treg Cells in Patients with Chronic Rheumatoid Arthritis. Arthritis Rheumatol. 68 (1), 103-116. doi:10.1002/art.39408

Wan, L., Liu, J., Huang, C., Chen, X., Zhao, L., Fan, H., et al. (2020). [Inflammation Caused by Different Immune Cell Subsets Is Involved in Bone Destruction of Rheumatoid Arthritis]. Xi Bao Yu Fen Zi Mian Yi Xue Za Zhi 36 (11), 1026-1031.

Wang, B., Sun, J., Li, X., Zhou, Q., Bai, J., Shi, Y., et al. (2013). Resveratrol Prevents Suppression of Regulatory T-Cell Production, Oxidative Stress, and Inflammation of Mice Prone or Resistant to High-Fat Diet-Induced Obesity. Nutr. Res. 33 (11), 971-981. doi:10.1016/j.nutres.2013.07.016

Wang, H. K., Yeh, C. H., Iwamoto, T., Satsu, H., Shimizu, M., and Totsuka, M. (2012b). Dietary Flavonoid Naringenin Induces Regulatory T Cells via an Aryl Hydrocarbon Receptor Mediated Pathway. J. Agric. Food Chem. 60 (9), 2171-2178. doi:10.1021/jf204625y

Wang, L., Wang, C., Jia, X., and Yu, J. (2018). Circulating Exosomal miR-17 Inhibits the Induction of Regulatory $\mathrm{T}$ Cells via Suppressing TGFBR II Expression in Rheumatoid Arthritis. Cell. Physiol. Biochem. 50 (5), 1754-1763. doi:10.1159/000494793

Wang, T., Sun, X., Zhao, J., Zhang, J., Zhu, H., Li, C., et al. (2015). Regulatory T Cells in Rheumatoid Arthritis Showed Increased Plasticity toward Th17 but Retained Suppressive Function in Peripheral Blood. Ann. Rheum. Dis. 74 (6), 1293-1301. doi:10.1136/annrheumdis-2013-204228

Wang, W., Shao, S., Jiao, Z., Guo, M., Xu, H., and Wang, S. (2012a). The Th17/Treg Imbalance and Cytokine Environment in Peripheral Blood of Patients with Rheumatoid Arthritis. Rheumatol. Int. 32 (4), 887-893. doi:10.1007/s00296-010$1710-0$

Wang, X., Yang, C., Xu, F., Qi, L., Wang, J., and Yang, P. (2019). Imbalance of Circulating Tfr/Tfh Ratio in Patients with Rheumatoid Arthritis. Clin. Exp. Med. 19 (1), 55-64. doi:10.1007/s10238-018-0530-5

Whitehouse, G., Gray, E., Mastoridis, S., Merritt, E., Kodela, E., Yang, J., et al. (2017). IL-2 Therapy Restores Regulatory T-Cell Dysfunction Induced by Calcineurin Inhibitors. Proc. Natl. Acad. Sci. U S A. 114 (27), 7083-7088. doi:10.1073/pnas.1620835114

Wu, Y. H., Liu, W., Xue, B., Zhang, L., Liu, X. Y., Liu, B., et al. (2016). Upregulated Expression of microRNA-16 Correlates with Th17/Treg Cell Imbalance in Patients with Rheumatoid Arthritis. DNA Cel Biol. 35 (12), 853-860. doi:10.1089/dna.2016.3349

Xie, M., Wang, J., Gong, W., Xu, H., Pan, X., Chen, Y., et al. (2019). NF-kB-driven miR-34a Impairs Treg/Th17 Balance via Targeting Foxp3. J. Autoimmun. 102, 96-113. doi:10.1016/j.jaut.2019.04.018

Xing, E., Guo, Y., Feng, G., Song, H., An, G., Zhao, X., et al. (2019). Effects of Dioscin on T Helper 17 and Regulatory T-Cell Subsets in Chicken Collagen Type II-Induced Arthritis Mice. J. Chin. Med. Assoc. 82 (3), 202-208. doi:10.1097/JCMA.0000000000000029

Xu, H., Zhao, H., Lu, C., Qiu, Q., Wang, G., Huang, J., et al. (2016). Triptolide Inhibits Osteoclast Differentiation and Bone Resorption In Vitro via Enhancing the Production of IL-10 and TGF-Betal by Regulatory T Cells. Mediators Inflamm. 2016, 8048170. doi:10.1155/2016/8048170

Xu, Y., Zhu, Q., Song, J., Liu, H., Miao, Y., Yang, F., et al. (2015). Regulatory Effect of Iguratimod on the Balance of Th Subsets and Inhibition of Inflammatory Cytokines in Patients with Rheumatoid Arthritis. Mediators Inflamm., 356040. doi:10.1155/2015/356040

Yagi, H., Nomura, T., Nakamura, K., Yamazaki, S., Kitawaki, T., Hori, S., et al. (2004). Crucial Role of FOXP3 in the Development and Function of Human $\mathrm{CD} 25+\mathrm{CD} 4+$ Regulatory $\mathrm{T}$ Cells. Int. Immunol. 16 (11), 1643-1656. doi:10.1093/intimm/dxh165

Yamagiwa, T., Fukunishi, S., Tachibana, T., Okamura, H., Yoshiya, S., and Kashiwamura, S. (2012). Abrogation of Treg Function Deteriorates Rheumatoid Arthritis. Mod. Rheumatol. 22 (1), 80-88. doi:10.1007/s10165-011-0476-x

Yan, Z., Garg, S. K., and Banerjee, R. (2010). Regulatory T Cells Interfere with Glutathione Metabolism in Dendritic Cells and T Cells. J. Biol. Chem. 285 (53), 41525-41532. doi:10.1074/jbc.M110.189944

Yang, M., Liu, Y., Mo, B., Xue, Y., Ye, C., Jiang, Y., et al. (2019). Helios but Not CD226, TIGIT and Foxp3 Is a Potential Marker for CD4(+) Treg Cells in Patients with Rheumatoid Arthritis. Cel. Physiol. Biochem. 52 (5), 1178-1192. doi:10.33594/000000080 
Yang, Y., Hu, X., Cheng, L., Tang, W., Zhao, W., Yang, Y., et al. (2017). Periplocoside A Ameliorated Type II Collagen-Induced Arthritis in Mice via Regulation of the Balance of Th17/Treg Cells. Int. Immunopharmacol. 44, 43-52. doi:10.1016/j.intimp.2016.12.013

Yao, X., Cao, Y., Ma, W., Hou, L., Zhong, Q., Huang, Y., et al. (2015). [Elevated Levels of Th17/regulatory T Cells in Peripheral Blood Are Associated with Disease Activity of Patients with Rheumatoid Arthritis]. Xi Bao Yu Fen Zi Mian Yi Xue Za Zhi 31 (1), 81-84.

Ye, J., Qiu, J., Bostick, J. W., Ueda, A., Schjerven, H., Li, S., et al. (2017). The Aryl Hydrocarbon Receptor Preferentially Marks and Promotes Gut Regulatory T Cells. Cell Rep. 21 (8), 2277-2290. doi:10.1016/j.celrep.2017.10.114

Yokota, Y., Shikano, A., Kuda, T., Takei, M., Takahashi, H., and Kimura, B. (2018). Lactobacillus Plantarum AN1 Cells Increase Caecal L. Reuteri in an ICR Mouse Model of Dextran Sodium Sulphate-Induced Inflammatory Bowel Disease. Int. Immunopharmacol. 56, 119-127. doi:10.1016/j.intimp.2018.01.020

Yuan, X., Tong, B., Dou, Y., Wu, X., Wei, Z., and Dai, Y. (2016). Tetrandrine Ameliorates Collagen-Induced Arthritis in Mice by Restoring the Balance between Th17 and Treg Cells via the Aryl Hydrocarbon Receptor. Biochem. Pharmacol. 101, 87-99. doi:10.1016/j.bcp.2015.11.025

Zamali, I., Rekik, R., Belhadj, H. N., Ben, H. A., Kammoun, O., Barbouche, M. R., et al. (2019). An Endogenous Aryl Hydrocarbon Receptor Ligand Enhances De Novo Generation of Regulatory T Cells in Humans. J. Leukoc. Biol. 105 (2), 291-295. doi:10.1002/JLB.2AB0518-205RR

Zare, H. R., Habibagahi, M., Vahdati, A., and Habibagahi, Z. (2015). Patients with Active Rheumatoid Arthritis Have Lower Frequency of nTregs in Peripheral Blood. Iran. J. Immunol. 12 (3), 166-175.

Zhang, R., Miao, J., Zhang, K., Zheng, Z., and Zhu, P. (2019). [Increased Percentage and Defective Inhibitory Function of CD4(+)CD25(-)FOXP3(+) T Cells in Synovial Fluid of Patients with Rheumatoid Arthritis]. Xi Bao Yu Fen Zi Mian Yi Xue Za Zhi 35 (11), 961-966.
Zhang, S. X., Wang, J., Wang, C. H., Jia, R. H., Yan, M., Hu, F. Y., et al. (2021). Lowdose IL-2 Therapy Limits the Reduction in Absolute Numbers of Circulating Regulatory T Cells in Rheumatoid Arthritis. Ther. Adv. Musculoskelet. Dis. 13, 1759720X211011370. doi:10.1177/1759720X211011370

Zhao, H., Xu, H., Zuo, Z., Wang, G., Liu, M., and Guo, M. (2018). Yi Shen Juan Bi Pill Ameliorates Bone Loss and Destruction Induced by Arthritis through Modulating the Balance of Cytokines Released by Different Subpopulations of T Cells. Front. Pharmacol. 9, 262. doi:10.3389/ fphar.2018.00262

Conflict of Interest: The authors declare that the research was conducted in the absence of any commercial or financial relationships that could be construed as a potential conflict of interest.

The reviewer CL declared a shared affiliation with one of the authors, HX, to the handling editor at time of review.

Publisher's Note: All claims expressed in this article are solely those of the authors and do not necessarily represent those of their affiliated organizations, or those of the publisher, the editors, and the reviewers. Any product that may be evaluated in this article, or claim that may be made by its manufacturer, is not guaranteed or endorsed by the publisher.

Copyright (C) $2021 \mathrm{Li}, \mathrm{Xu}$, Huang, Luo, Lv, Lu and Xiao. This is an open-access article distributed under the terms of the Creative Commons Attribution License (CC BY). The use, distribution or reproduction in other forums is permitted, provided the original author(s) and the copyright owner(s) are credited and that the original publication in this journal is cited, in accordance with accepted academic practice. No use, distribution or reproduction is permitted which does not comply with these terms. 